IZA DP No. 7166

Revisiting the Minimum Wage-Employment Debate: Throwing Out the Baby with the Bathwater?

David Neumark J.M. Ian Salas

William Wascher

January 2013 


\title{
Revisiting the Minimum Wage- Employment Debate: Throwing Out the Baby with the Bathwater?
}

\author{
David Neumark \\ $U C I, N B E R$, and IZA \\ J.M. Ian Salas \\ $\mathrm{UCl}$ \\ William Wascher \\ Federal Reserve Board \\ Discussion Paper No. 7166 \\ January 2013 \\ IZA \\ P.O. Box 7240 \\ 53072 Bonn \\ Germany \\ Phone: +49-228-3894-0 \\ Fax: +49-228-3894-180 \\ E-mail: iza@iza.org
}

\begin{abstract}
Any opinions expressed here are those of the author(s) and not those of IZA. Research published in this series may include views on policy, but the institute itself takes no institutional policy positions. The IZA research network is committed to the IZA Guiding Principles of Research Integrity.

The Institute for the Study of Labor (IZA) in Bonn is a local and virtual international research center and a place of communication between science, politics and business. IZA is an independent nonprofit organization supported by Deutsche Post Foundation. The center is associated with the University of Bonn and offers a stimulating research environment through its international network, workshops and conferences, data service, project support, research visits and doctoral program. IZA engages in (i) original and internationally competitive research in all fields of labor economics, (ii) development of policy concepts, and (iii) dissemination of research results and concepts to the interested public.
\end{abstract}

IZA Discussion Papers often represent preliminary work and are circulated to encourage discussion. Citation of such a paper should account for its provisional character. A revised version may be available directly from the author. 


\title{
ABSTRACT
}

\section{Revisiting the Minimum Wage-Employment Debate: Throwing Out the Baby with the Bathwater?}

\begin{abstract}
We revisit the minimum wage-employment debate, which is as old as the Department of Labor. In particular, we assess new studies claiming that the standard panel data approach used in much of the "new minimum wage research" is flawed because it fails to account for spatial heterogeneity. These new studies use research designs intended to control for this heterogeneity and conclude that minimum wages in the United States have not reduced employment. We explore the ability of these research designs to isolate reliable identifying information and test the untested assumptions in this new research about the construction of better control groups. Our evidence points to serious problems with these research designs. We conclude that the evidence still shows that minimum wages pose a tradeoff of higher wages for some against job losses for others, and that policymakers need to bear this tradeoff in mind when making decisions about increasing the minimum wage.
\end{abstract}

JEL Classification: J23, J38

Keywords: minimum wage, employment, control groups

Corresponding author:

David Neumark

Department of Economics

3151 Social Science Plaza

University of California, Irvine

Irvine, CA 92697

USA

E-mail: dneumark@uci.edu

\footnotetext{
* We are grateful to Marianne Bitler, Charles Brown, Jeffrey Thompson, and Rob Valletta for helpful comments, and Arin Dube and his co-authors for sharing their data and computer code. Neumark and Salas' work on this project received support from the Employment Policies Institute (EPI). The views expressed in this paper do not necessarily reflect the views of EPI or of the Board of Governors of the Federal Reserve System, and the authors have retained full editorial control of the paper's content and conclusions. All data and programs used in this research will be available from the authors upon request when the research is completed. This paper was prepared for presentation at the conference "Celebrating the Centennial of the U.S. Department of Labor," November 9, 2012, Washington, DC.
} 


\section{Introduction}

Debates about the economic effects and the merits of the minimum wage date back at least as far as the establishment of the Department of Labor as a cabinet-level agency in 1913. Given the absence of empirical evidence on the effects of minimum wages in the early 1900s, the initial debates were largely based on theoretical reasoning. The neoclassical school (including John Bates Clark, H. B. Lees-Smith, and Frank Taussig) argued that wage levels were determined by workers' productivity and that minimum wages would reduce employment among low-skilled workers. In contrast, the progressives (such as Sidney Webb, Rogers Seager, and John Commons) argued that minimum wages were necessary to prevent the widespread exploitation of lower-skilled workers by employers with greater bargaining power over wages, would encourage workers to increase their efforts, and would boost consumers’ purchasing power and thus raise aggregate demand.

A similar debate erupted after the federal minimum wage was enacted in 1938 . The main protagonists at that time were George Stigler (1946) and Fritz Machlup (1946), representing the “marginalist” school of economists, and Richard Lester (1946), who was considered an "institutionalist" economist. Again, the debate was primarily about the appropriate theoretical model of the labor market, although both sides also attempted to bolster their arguments with empirical analyses. Stigler and Machlup took the neoclassical position that minimum wages reduce employment, while Lester argued that product demand rather than wage rates was by far the most important factor determining employment so that fairness was the more appropriate consideration in setting a wage floor. ${ }^{1}$

Economists and statisticians from the Department of Labor have contributed importantly to the empirical literature on the economic effects of minimum wages over the past century. One of the first statistical analyses of minimum wages in a U.S. state was conducted by Marie Obenauer and Bertha von der Nienburg of the Bureau of Labor Statistics (BLS) in 1915, who examined the effects of a minimum wage for women that was introduced in Oregon between October 1913 and February 1914. For this

\footnotetext{
${ }^{1}$ Stigler acknowledged the possibility that minimum wages could raise employment in a labor market with a monopsonistic employer, an idea that would become more prominent in the 1990s. However, his own view was that low-wage markets were generally competitive in nature and thus that such monopsony effects were unlikely to be important in U.S. labor markets.
} 
study, which was a precursor to the case study approach that constitutes a key branch of the empirical literature that blossomed after 1990, the BLS collected data on employment and wages by age and sex, as well as sales, from 40 retail stores in Oregon for March and April of 1913, about five months prior to the introduction of the minimum wage in the state, and for March and April of 1914, about five months after the minimum wage took effect. The study then compared the changes in the employment of women and men over that period. Although quite cautious about the power of their difference-in-differences statistical approach (for example, the analysis was complicated by a recession in 1914 and by a legislated reduction in working hours for women), the study concluded that the minimum wage had a positive effect on wages and little or no effect on women's employment in the aggregate, but that stores substituted teenage girls (who were subject to a lower minimum wage) for adult women in lesser-skilled jobs.

Similarly, some of the first empirical analyses of the federal minimum wage law enacted in 1938 were undertaken by analysts from the Wage and Hours and Public Contracts Division of the Department of Labor. In particular, the Department conducted a series of studies examining the effects of the new minimum wage on wages and employment in certain industries, either by comparing changes in wages and employment in plants in low-wage southern states with their counterparts in higher-wage northeastern states or by comparing employment changes in plants with different levels of average wages before the federal minimum wage took effect. These studies, which tended to find modest disemployment effects, were followed by similar efforts by the Department to assess the effects of increases in the federal minimum wage in the 1940s and 1950s. The findings of these studies were at the center of a vigorous debate between Richard Lester and John Peterson on the merits of the minimum wage in the late 1950s and early 1960s (Lester, 1960; Peterson, 1957, 1959, 1960).

Over time, empirical analyses, especially the time-series studies conducted in the 1960s and 1970s, increasingly found that minimum wages tended to reduce employment among teenagers, who were viewed as a proxy for low-skilled labor more generally. A famous paper by Charles Brown, Curtis Gilroy, and Andrew Kohen, published in 1982, surveyed the existing literature on minimum wages and established the "consensus" that a 10 percent increase in the minimum wage would reduce teenage 
employment by 1 to 3 percent (Brown et al., 1982). Following that study, economists began to coalesce around the idea that minimum wages have adverse effects on low-skilled employment.

That consensus turned out to be relatively short-lived. After a decade of near-silence, the debate over the employment effects of the minimum wage reemerged in the early 1990s with the publication of a special issue of the Industrial and Labor Relations Review (ILRR). This issue featured four studies that used different analytical approaches and that took advantage of the increasing divergence of minimum wages at the state level to estimate the employment effects of minimum wages. These studies, which formed the basis for what is sometimes termed the "new minimum wage research,” were diverse in their findings, ranging from disemployment effects similar to the earlier consensus (Neumark and Wascher 1992), to no effect on employment (Card 1992a) to a positive effect of the minimum wage on employment (Card 1992b; Katz and Krueger 1992).

The ILRR symposium launched a new body of contemporary research on the minimum wage, much of which was summarized in our 2008 book Minimum Wages (Neumark and Wascher, 2008). In that book, our evaluation and summary of the evidence concluded that “... [M]inimum wages reduce employment opportunities for less-skilled workers, especially those who are most directly affected by the minimum wage” (Neumark and Wascher, 2008, p. 6). This paper, in part, extends this evaluation and summary to the present by evaluating two recent studies that have questioned the empirical methods and conclusions in much of the recent literature (Allegretto et al., 2011; Dube et al., 2010).

The key question raised by these recent studies is how researchers can reliably identify the employment effects of the minimum wage - a question that is nearly as long-running as the debate over the minimum wage. In particular, the identification of minimum wage effects requires both a sufficiently sharp focus on potentially affected workers and the construction of a valid counterfactual "control group" for what would have happened absent increases in the minimum wage. The latter is critical to account for other influences on the employment of potentially affected workers that may be confounded with the effects of changes in the minimum wage. In the research of the past two decades, economists have frequently used state variation in minimum wages to generate comparisons between states with different 
minimum wage levels or changes at the same point in time, to avoid confounding minimum wage effects with other aggregate influences on the labor market (e.g., the national business cycle).

Dube et al. (2010, hereafter DLR) and Allegretto et al. (2011, hereafter ADR) have put forward a severe critique of the state panel-data approach, including the work discussed at length in Neumark and Wascher (2008). The essence of the argument in DLR and ADR is summarized in a review of Minimum Wages by Dube (2011), which draws heavily on the findings from the two papers he co-authored:

“...[V]ariation over the past two decades in minimum wages has been highly selective spatially, and employment trends for low-wage workers vary substantially across states ... This has tended to produce a spurious negative relationship between the minimum wage and employment for low wage workers - be it for sectors such as restaurant and retail or for demographic groups such as teenagers” (Dube, 2011, p. 763).

Commenting on the econometric evidence more specifically, Dube writes: "Even simple regional controls and trends produce employment effects close to zero, as do more sophisticated approaches such as comparing contiguous counties across policy boundaries - which essentially embeds the "case study" approach within panel data analysis ...” (pp. 763-4). Dube defines his and his co-authors’ studies as “a fourth generation of recent work that tries to make sense of the sometimes contradictory evidence” (p. 763), and argues that their work raises serious questions about the conclusions drawn by Neumark and Wascher - and much of the broader literature - regarding the employment effects of minimum wages.

Echoing Dube, ADR argue without reservation that their results overturn the conclusion that minimum wages reduce employment of low-skilled workers: "Interpretations of the quality and nature of the evidence in the existing minimum wage literature ... must be revised substantially. Put simply, our findings indicate that minimum wage increases - in the range that have been implemented in the United States - do not reduce employment among teens” (ADR, 2011, p. 238). Similarly, DLR conclude that there are "no detectable employment losses from the kind of minimum wage increases we have seen in the United States” (DLR, 2010, p. 962).

Our principal goal in this paper is to evaluate this new research because of the strong challenge it poses to the large body of prior research that found that minimum wages reduce employment of lowskilled workers. As the description of the work above suggests, the central element of this new research is the issue of how to construct counterfactuals for the places where minimum wages are increased. The 
authors of both studies argue that one must compare places that are geographically proximate to have valid controls, because, according to them, minimum wage changes are correlated with unobserved economic shocks to areas that can confound the estimation of minimum wage effects. Consequently, much of the analysis focuses on the validity of this criticism, and on the approaches these studies take to address this potential problem. The overriding concern we have with these studies is that their research designs, out of concerns about avoiding minimum wage variation that is potentially confounded with other sources of employment change, discard a great deal of valid identifying information - throwing out the identifying "baby" along with, or worse yet instead of, the contaminated "bathwater." Our findings, in a nutshell, indicate that neither the conclusions of these studies nor the methods they use are supported by the data.

II. Recent Research Challenging the Conclusion that Minimum Wages Reduce the Employment of Low-

\section{$\underline{\text { Skilled Workers }}$}

Of the two papers by Dube and his colleagues, the analysis in ADR is the most direct extension of the state panel-data approach used extensively in the existing research on the employment effects of minimum wages. In this study, ADR focus on standard specifications of minimum wage effects on the employment of teenagers, using information on state-level minimum wages and individual-level data from the Current Population Survey (CPS) from 1990-2009. When they estimate a model that includes state and period fixed effects along with other standard controls, they find a negative employment effect of minimum wages. However, when they include either state-specific linear trends or Census division $\times$ period interactions (or both), the estimated employment effects of minimum wages fall to approximately zero and are statistically insignificant.

In contrast, DLR’s analysis focuses primarily on restaurant employment using county-level Quarterly Census of Employment and Wages (QCEW) data from 1990-2006. Although they present some results from panel data models that include state-specific trends and Census division $\times$ period interactions (along with county fixed effects), their core analysis uses a research design based on crossborder county pairs. Their specification includes county pair $\times$ period interactions intended to control for shocks common to both counties, and thus identifies the effect of minimum wages from differences in 
employment changes in paired counties on either side of a state border. This narrowing of identification

to within-county-pair comparison causes the employment effects to go from negative and significant to small and insignificant.

Closely related findings are reported in Addison et al. (forthcoming). They also use QCEW data, focusing on nearly the same period (1990-2005) and on nearly the same sector. With regard to DLR's first set of analyses, about the only difference is that the authors include county-specific linear trends. However, the qualitative conclusion is the same: they find negative employment effects when they include only county and quarter fixed effects, but no evidence of employment effects when they include county-specific trends. Similarly, in a 2009 paper these same co-authors estimate these models for various parts of the retail sector with county-specific time trends, and also do the same border-county analysis as in DLR, with similar findings. ${ }^{2}$

To put this new evidence in context, it is useful first to assess the implications of these results for the existing state-level panel studies, especially since ADR and DLR have explicitly used their findings to cast doubt on the evidence from these studies. With regard to DLR's paper, it is worth noting that very little of the existing work is on the restaurant sector or the retail sector more broadly, so new evidence on restaurant or retail employment does not address the far more pervasive evidence on teens or other very low-skilled workers. For one thing, the evidence from the earlier research is strongest for individuals most directly affected by the minimum wage, and many workers within the restaurant or retail sector earn

\footnotetext{
${ }^{2}$ Addison et al. (2011) use similar methods to try to estimate the effects of minimum wages in the United States during the Great Recession, and conclude that there is not evidence of disemployment effects. However, perhaps because of the short time period studied and the large movements in aggregate labor market outcomes during that period, the standard errors on the point estimates are so large as to be uninformative. For example, in some cases (e.g., teens) the authors find negative employment effects that are in the earlier "consensus" range but that are not statistically significant. There are similar concerns about the results reported in Hirsch et al. (2011), who study the effects of the recent federal minimum wage increases on employment at "quick-service" restaurants in Georgia and Alabama. They report estimated employment elasticities, with respect to the wage cost increases induced by the higher minimum wage, that are sometimes positive and sometimes negative, but that also have large standard errors (about 0.4-0.5). They also estimate the effects of the cumulative increase - which are not reported in the paper but were supplied in a personal communication from Barry Hirsch - and find large and negative effects (ranging from -0.8 to -1.7$)$ that are statistically insignificant, suggesting that the main problem may be uninformative data.
} 
well more than the minimum wage. For another, the minimum wage can lead employers to substitute higher-skilled workers for lower-skilled workers without reducing net employment very much. ${ }^{3}$

ADR's research focuses primarily on teenagers and can therefore be viewed as posing more of a direct challenge to the findings from the state-level panel data approach. Even in this case, however, the potential for labor-labor substitution among teenagers with different skill levels means that the effects of minimum wages on overall teenage employment can be difficult to detect; for example, larger gross disemployment effects among the least-skilled teens may be masked by inflows of other teens into employment. ${ }^{4}$ Indeed, the most recent estimates Neumark and Wascher have presented for teenagers show negative effects only for male teens when disaggregating by sex, and only for black or Hispanic male teens when disaggregating male teens into whites vs. black or Hispanic (Neumark and Wascher, 2011). And other work, focused on the lowest-wage workers rather than on teenagers per se, finds negative employment effects for them as well (Neumark et al., 2004). Nonetheless, a negative effect of minimum wages on employment of the lowest skilled ought to imply negative effects for at least some groups of teenagers, and for the sample period they study, ADR do find that a panel data model with only state and year fixed effects produces evidence of disemployment effects in the range of past estimates. Thus, their finding that this conclusion is sensitive to whether state-specific linear trends or region $x$ period interactions are included in the specification poses a challenge to the conventional view of

\footnotetext{
${ }^{3}$ DLR acknowledge this possibility, noting that “... [O]ur data do not permit us to test whether restaurants respond to minimum wage increases by hiring more skilled workers and fewer less skilled ones” (p. 962). However, the existing literature suggests that such labor-labor substitution is important. For example, Fairris and Bujanda (2008) find evidence of labor-labor substitution by city contractors in response to the Los Angeles living wage ordinance a different kind of mandated wage floor. In addition, in a study of personnel records from over 600 establishments of a single large retail firm, Giuliano (forthcoming) finds that large minimum wage-induced increases in the wage rates of teenagers relative to adults were associated with increases in employment for teenagers from higher socioeconomic status zip codes and decreases in the employment of young adults (ages 20-22). Moreover, data on the individual workers who were laid off and on store performance indicated that at some stores the teens that were hired were of higher quality than teens already employed at the stores, and of higher quality than the young adults at the stores. Similar evidence consistent with this substitution from low-skilled adults to possibly higher-skilled teenage students (in food-service occupations) is reported in Lang and Kahn (1998). Finally, Neumark and Wascher (1996) find evidence of this substitution among teens, with a higher minimum wage drawing those enrolled in school and working part-time into full-time work, while pushing those working full-time and not enrolled in school out of jobs into "idleness" (neither working nor employed).

${ }^{4}$ The focus on teenagers is, to some extent, a vestige of the old time-series literature. Because labor economists had to aggregate employment data by age group, it made sense to look mainly at teenagers because minimum wage workers comprised such a small share of older age groups.
} 
minimum wage employment effects. We next turn to a more thorough explanation of their analysis, as well as an evaluation of it; we then do the same for the DLR study.

\section{Evaluation of the Evidence}

Allegretto et al. (2011)

As noted above, ADR find that the negative effects estimated from standard state-level panel data specifications of the effects of minimum wages on the employment of teenagers are sensitive to including either state-specific linear trends or Census division $\times$ period interactions (or both). This leads them to conclude that models with only state and year fixed effects "fail to account for heterogeneous employment patterns that are correlated with selectivity among states with minimum wages. As a result, the estimates are often biased and not robust to the sources of the identifying information” (p. 205). More specifically, they argue that "Lack of controls for spatial heterogeneity in employment trends generates biases toward negative employment elasticities in national minimum wage studies” (p. 206).

We re-examine these findings with the same CPS data, using a specification with the same aggregate variables they include. The sample is extended to take account of newer data (which does not change the basic conclusions), and, whereas ADR use individual-level data with clustering at the state level, we aggregate the data to the state level by quarter, also clustering at the state level. ${ }^{5}$ The minimum wage, here and throughout, is defined as the higher of the state and federal minimum.

As can be seen in Table 1, the results closely mirror what ADR found (their Table 3). In the model that includes the standard labor market controls along with state and time fixed effects, ${ }^{6}$ the estimated employment elasticity with respect to the minimum wage is -0.165 , significant at the $1 \%$ level (ADR estimate an elasticity of -0.12 , significant at the $5 \%$ level). ${ }^{7}$ When either state-specific linear trends are added, region $\times$ quarter interactions are added, or both are added simultaneously, the estimated

\footnotetext{
${ }^{5}$ Aggregated data are used because this form is more convenient for some of the analyses that follow, particularly those that focus on the time-series patterns in the data by state. Moreover, because the identifying information is the state-level minimum wage variation, the use of state-level data for the other variables should be inconsequential. ${ }^{6}$ Because ADR use micro-data rather than state-level data, they also include controls for individual demographic characteristics.

${ }^{7}$ The specification is in logs so the estimated coefficient is the elasticity; in contrast, ADR estimate linear probability models for employment with the log of the minimum wage on the right-hand side. They report the magnitude and statistical significance of the estimated linear probability coefficients, and then the implied elasticity.
} 
elasticities become considerably smaller (ranging from -0.098 to 0.009) and are statistically insignificant. The same is true in the ADR results (their Table 3), where the estimates are statistically insignificant and the estimated elasticities range from -0.036 to $0.047 .^{8}$

This evidence suggests that conclusions about the effects of minimum wages on teenagers may not always be robust to the type of identifying variation used to estimate these effects: differences in within-state variation associated with minimum wage changes relative to other states in the same year; differences in within-state variation relative to other states in the same year that is also net of statespecific linear trends; or (essentially) differences in within-state variation relative to states in the same Census division.

Interestingly, though, the only time ADR question the validity of their approach is with regard to their evidence of statistically significant negative effects on hours of Hispanic teens. In response to these findings, they write "the puzzling and somewhat fragile evidence for Hispanic teens may be driven by the concentration of Hispanic teens in a small number of Census divisions, on the one hand, and the small number of Hispanic teens in most states at the beginning of the sample period. These patterns reduce the ability to estimate effects for this group robustly within our methodology” (2011, p. 234). Similarly, they argue that “[I]ncluding spatial controls renders the estimates for Latinos particularly imprecise and fragile” (p. 208). But in their Table 7, on which this discussion is based, the estimates are actually more precise for Hispanics than for blacks, yet they conclude that "controlling for spatial heterogeneity by using within-Census division variation is particularly important when looking at African-American employment effects” (p. 234).

Rather than judgmentally deciding where and when to include area-specific time trends or region $\times$ period dummies - arguably based on the answer - researchers should examine what sources of variation provide better estimates of the effects of minimum wages. In the context of this paper, this preferred

\footnotetext{
${ }^{8}$ We also experimented with a specification that added controls for the adult wage and adult employment-topopulation ratio, and defining these variables (and the adult unemployment rate) for skilled adults aged 25-64 with more than a high school education. The estimated minimum wage effects were very similar to those reported in Table 1.
} 
approach entails exploring the implications of including state-specific trends or region $\times$ time interactions and whether doing so results in more or less reliable estimates of minimum wage effects.

State-Specific Trends. We first focus on the evidence regarding state-specific trends, which are intended to control for longer-run influences not captured in the other control variables. It has become standard practice to assess the robustness of panel data estimates of state policy effects to the inclusion of state-specific trends, including in the minimum wage literature (e.g., Neumark and Wascher, 2004 and 2011). If these kinds of analyses deliver robust results that are insensitive to the inclusion of these trends, then they can clearly bolster the evidence. If, however, they point to different evidence, then the researcher has to seriously explore which analysis is most convincing, rather than simply relying on a priori hunches.

The first thing to note is that Neumark and Wascher (2011), using data from 1994-2007, found that the estimated effects of minimum wages on teen employment are negative and significant in specifications that include state-specific trends. ${ }^{9}$ This result raises the question as to whether there is something different about the sample period ADR studied that makes it problematic to include linear state-specific trends. An obvious candidate is the severe recession at the end of their sample period, as is the recession at the beginning of their sample period (in 1990 and 1991). In models that include statespecific trends, the recessions at the beginning and end of ADR's sample period could have a large influence on the estimated state-specific trends. If the recessions have purely an aggregate influence that is common across all states, this will not happen, as the year effects will absorb this common influence. But if the recessions led to cross-state deviations between teen employment rates and aggregate labor market conditions, then the estimated longer-term trends in teen employment could be biased. This, in turn, could lead to misclassification of periods in which teen employment was high or low relative to the predicted values net of the minimum wage, and hence influence the estimated minimum wage effects for reasons having nothing to do with the longer-run trends for which the specification is trying to control.

\footnotetext{
${ }^{9}$ And although not reported in a table, we verified that with the data used here, this result still holds. Estimating the model from Table 1 with data from 1994-2007:Q2, the minimum wage effect (standard error) is $-0.148(0.060)$ without state linear trends, and -0.229 (0.095) with them.
} 
To illustrate the potential problem, Figure 3 displays some results for California. The model is first estimated including the state-specific trends, for the period excluding the recessions (1994-2007:Q2). The upper-left panel shows the actual residuals for this period, and then the prediction errors for the two recessionary periods. There are sizable deviations of teen employment from the model's predicted values during these two recessionary periods, which could have a strong influence on the estimated state-specific trends in samples that included those periods. In particular, teen employment was considerably higher than would have been predicted by the regression model in the early-1990s recession, whereas the opposite was true during the Great Recession (presumably reflecting the different industries affected by the two recessions).

The consequences of including the recessionary periods are illustrated in the remaining three panels of the figure, which show the residuals from the fitted regression model when the estimation period is extended to include one or both recessionary periods. In these panels, the deviations of the actual values of teen employment from the fitted values (i.e., the residuals) are much smaller for the recessionary periods than in the upper-left panel, and these residuals are more centered on zero. Correspondingly, the estimates of the state-specific trends over the non-recessionary period are strongly influenced by the inclusion of the recessionary periods. For example, in the upper-right and two lower panels the regressions of the residuals on a time trend for the 1994-2007:Q2 subperiod have slopes that are quite different from zero, indicating that the residuals from the recessionary periods are influencing the estimated trends. ${ }^{10}$ Thus, including the strong recessionary periods of the early 1990s and the Great Recession in the estimation could bias the state-specific trend estimates away from the values associated with longer-term factors not captured by the other controls and thus potentially confound the estimates of the employment effects of minimum wages.

One approach to this problem is to allow the state-specific trends to be of a higher order than linear. Higher-order trends should be better than linear trends at capturing the variation induced by the recessions - especially third-order and higher polynomials that allow for multiple inflection points.

\footnotetext{
${ }^{10}$ In the upper-left panel, where the model is estimated for 1994-2007:Q2, a regression of the residuals for this period on a time trend will, by construction, yield a zero coefficient, because the model includes a separate time trend for each state, and OLS residuals are orthogonal to the regressors.
} 
Estimates for the full sample period that include these higher-order trends are reported in columns (1)-(4)

of Table 2. (The comparable estimates with no state-specific trends and with linear trends are in columns (1) and (2) of Table 1.) The table shows that as long as third-order polynomials or higher are used, the estimated effects of the minimum wage on teen employment are negative and significant, with point estimates very similar to the estimates for the standard model that excludes state-specific trends - and similar to the estimates for the subsample excluding the beginning and ending recessionary periods. ${ }^{11}$

An alternative approach is to estimate the state-specific linear trends using only the data from the subsample that excludes the recessionary periods and then include those trend estimates in a regression over the full sample period. To implement this approach, note that the standard regression model with state-specific linear trends is:

$$
\mathrm{Y}_{\mathrm{it}}=\alpha+\pi \mathrm{MW}_{\mathrm{it}}+\mathrm{X}_{\mathrm{i}} \beta+\mathrm{S}_{\mathrm{i}} \gamma+\mathrm{T}_{\mathrm{t}} \delta+\mathrm{S}_{\mathrm{i}} \cdot \mathrm{t} \cdot \theta+\varepsilon_{\mathrm{it}} .
$$

We can simply estimate this model with OLS. If we knew $\theta$, however, we could instead form the dependent variable $\mathrm{Y}_{\mathrm{it}}-\mathrm{S}_{\mathrm{i}} \cdot \mathrm{t} \cdot \theta$, and estimate the model

$$
\mathrm{Y}_{\mathrm{it}}-\mathrm{S}_{\mathrm{i}} \cdot \mathrm{t} \cdot \theta=\alpha+\pi \mathrm{MW}_{\mathrm{it}}+\mathrm{X}_{\mathrm{i}} \beta+\mathrm{S}_{\mathrm{i}} \gamma+\mathrm{T}_{\mathrm{t}} \delta+\varepsilon_{\mathrm{it}} .
$$

This specification will give us the same estimates, although the standard errors would be understated because the sampling variation in estimating $\theta$ would be ignored.

Following this intuition, we can define a subperiod of the sample, $t_{1}$ to $t_{2}$, and estimate equation (1) for this subsample. The estimated state-specific trends for this subsample can be retained, denoted by the vector $\hat{\theta}_{12}$. The dependent variable for the full sample period can then be detrended using $\hat{\theta}_{12}$, and equation (2) estimated over the full sample for the detrended data. This lets us remove the state-specific linear trends estimated for the subperiods excluding the steep recessions, rather than the whole sample period, while still using the whole sample to estimate minimum wage effects. The only complication is that the standard errors have to be corrected to account for the sampling variation in $\hat{\theta}_{12}$. This is done by using block-bootstrapping by state, to account for the non-independence of observations within states.

\footnotetext{
${ }^{11}$ The results are very similar using the slightly shorter sample period that ADR use. The point estimates are also similar, although a bit less precise, with 6th- or 7th-order polynomials; for these specifications, the estimated minimum wage elasticity ranges from -0.14 to -0.17 , and is significant at the ten-percent level in three out of four cases (including both specifications using ADR's sample).
} 
As reported in column (5) of Table 2, when the panel data model with state-specific trends is estimated in this way the estimated effects of minimum wages are much more strongly negative and are statistically significant: The estimated minimum wage effect remains negative and significant, with an estimate of -0.178 , compared with -0.165 in Table 1 without the state-specific linear trends and -0.074 (and insignificant) with them. Thus, removing the state-specific trends in a way that excludes the recessions at the beginning and end of the sample leads to stronger evidence of disemployment effects. ${ }^{12}$

A third approach is to estimate the model over the full sample period after pre-filtering the data to remove state-specific trends. This pre-filtering is done in two ways: (1) calculating the trend in each variable as a linear spline between consecutive business cycle peaks as defined by the NBER (and extrapolating the trends over the relevant range of the sample before the first business cycle peak and after the last business cycle peak); ${ }^{13}$ and (2) passing each data series (by state) through a Hodrick-Prescott filter using the standard smoothing parameter for quarterly data and extracting the non-trend component of the series. ${ }^{14}$ Estimates of the model using the data detrended in each of these ways are shown in columns (6) and (7) of Table 2. Similar to the results in column (5), the coefficients on the minimum wage variable are more strongly negative than when linear trends are included in the model estimated over the full sample period (as in the second column of Table 1).

\footnotetext{
${ }^{12}$ A slightly more complicated version of this estimator is also estimated, which allows the state-specific trends to differ before and after 2000:Q4 (near the peak of the economy before the 2001 recession). In this specification, the trend lines are restricted to be joined in that quarter so that the trend can shift, but not the state effects. The estimates from this augmented specification were very similar to those in column (5) of Table 2.

${ }^{13}$ The rationale for this is perhaps best illustrated by the problem demonstrated in Figure 1, namely that recessions can produce quite different patterns in the teen employment variable. Doing this calculation from peak-to-peak is a simple way to avoid this problem.

${ }^{14}$ The Hodrick-Prescott (or HP) filter is a common technique used in the empirical macroeconomics literature to remove stochastic trends from aggregate time-series data prior to estimation by statistical procedures that assume stationarity (see, for example, Hodrick and Prescott, 1997). It is effectively a two-sided symmetric moving average filter that extracts the trend by smoothing the time series, with the degree of smoothing specified in advance by the researcher. The smoothing parameter $(\lambda)$ penalizes variations in the growth rate of the trend component and can range from zero (in which case there is no smoothing) to $\infty$ (in which case the smoothed trend is linear). For quarterly data, $\lambda$ is typically set to 1600 , based on research by Ravn and Uhlig (2002) on how the optimal smoothing parameter changes for data of varying frequencies. Cogley and Nason (1995) find that the HP filter performs well for time-series that are stationary or trend stationary, but can generate spurious business cycle periodicity for time series that are difference stationary. Accordingly, each series in the regression was tested at the state level for the presence of a unit root using the standard Dickey-Fuller test, and in most cases we were able to characterize the time series as stationary or trend stationary.
} 
Thus, among the analyses we have carried out, the only way to generate the results in ADR (2011) - that inclusion of state-specific time trends eliminates the negative effects of minimum wages - is to include in the sample period the recessionary period of the early 1990s or the recent Great Recession, and to let these periods have a strong influence on the estimated trends by use of a highly restrictive specification for those trends. Moreover, the evidence suggests that the linear state-specific trends used by ADR for these sample periods are influenced by the recessions in ways that apparently contaminate their estimates of minimum wage effects on teen employment. ${ }^{15}$ More generally, our evidence shows that the estimated effects of minimum wages on teen employment are negative and significant with or without the inclusion of controls for long-term trends in teen employment when those long-term trends are estimated in ways that are not highly sensitive to the business cycle. This evidence invalidates ADR's (2011) conclusion that "Lack of controls for spatial heterogeneity in employment trends generates biases toward negative employment elasticities in national minimum wage studies” (p. 206). ${ }^{16}$

To support their inclusion of linear trends, ADR point to various longer-term influences on teen employment that are not included in the standard specification. Specifically, they cite research by Smith (2010) suggesting that technological change may have led to an increased supply of adult workers for low-skill jobs that had been commonly held by youth (their footnote 2). And they cite research by Aaronson et al. (2007) and the CBO (2004) suggesting that teen employment may have been influenced by changes in financial aid for college students, the attractiveness of college, or technological shifts that have lowered market wages for teens. However, given the problems we have identified with simply assuming that these kinds of factors can be captured in linear state-specific trends, it would clearly be

\footnotetext{
${ }^{15}$ Addison et al. (2009) discuss this issue in somewhat more detail. They note that Sabia (2008) estimates models for retail employment (using CPS data from 1979-2004) and finds negative employment effects without state trends, but not when trends are included (in which case the estimates become positive). They write that Sabia argues against including these trends, quoting him as saying that the trends may reduce "potentially important identifying information" (p. 88, cited in footnote 18). However, they go on to argue that because the standard errors fall when the trends are included, this is not a concern. This argument is sophistic. If the state-specific trends are misestimated because of the recessionary periods, they may still lead to more precise estimates - even though their inclusion may not yield reliable estimates of minimum wage effects.

${ }^{16}$ We also considered whether using more flexible functions of the regression controls would reduce the sensitivity of the state-specific trends to the recessionary periods. We added second- and third-order terms of the controls and cross-products of the controls. The addition of these variables did not qualitatively alter the estimates reported in Table 1. The estimates without the state-specific linear trends were similar to those in Table 1, as were the (smaller, in absolute value) estimates with the trends added.
} 
preferable to incorporate data on the potentially omitted factors rather than simply including trends and interpreting the results as reflecting these factors.

Division $\times$ Period Interactions. The preceding analysis suggests that ADR's claim that underlying trends that vary by state generate spurious evidence of negative minimum wage effects on teen employment is clearly not true. However, Table 1 also shows that the inclusion of Census division $\times$ period interactions renders the estimated minimum wage effects smaller and statistically insignificant. As a prelude to delving into what to make of this result, we start by considering the arguments that ADR use to support their view that including these interactions is necessary to account for the spatial heterogeneity that they think biases estimates of minimum wage effects in the standard panel data approach. In this regard, they appeal to Figure 1 and Table 1 (from their paper) to argue that "employment rates for teens vary by Census division and differentially so over time” (p. 206).

One particular hypothesis they suggest is that the endogeneity of minimum wages increases generates a bias towards finding negative employment effects. As evidence, they cite Reich (2009), who ADR claim shows that minimum wages "are often enacted when the economy is expanding and unemployment is low. But, by the time of implementation, the economy may be contracting and unemployment increasing, possibly leading to a spurious time series correlation between minimum wages and employment” (p. 212, italics added). In fact, Reich actually argues the opposite, based on his evidence: "Minimum-wage increases are voted almost without exception and are mostly implemented in times of growing employment. This pattern holds for both federal and state increases” (p. 366, italics added). Thus, if anything, Reich's evidence points to possible spurious positive correlations that would bias estimated minimum wage effects toward zero. ${ }^{17}$ ADR's argument is also problematic because the regression model already controls for aggregate state-level labor market conditions via the unemployment rate, and includes time dummies that will capture aggregate changes not picked up in the state-level controls.

\footnotetext{
${ }^{17}$ Moreover, a recent study by Baskaya and Rubinstein (2011) that looks specifically at the endogeneity problem using an instrumental variables approach supports the hypothesis that state minimum wage increases are procyclical, so that failure to account for endogeneity could mask the negative effect of minimum wages, biasing the estimates toward zero.
} 
That said, there could be other omitted factors that drive patterns of teen employment differentially by Census division, and these could be correlated with minimum wage changes in any direction. And the sensitivity of the estimates to the inclusion of the division $\times$ period interactions is something that is important to understand further - in particular whether the disappearance of minimum wage effects when these interactions are included is evidence of the need to control for spatial heterogeneity, as ADR argue.

An important concern with their approach, though, relates to the implications of augmenting the specification to include more than 1,900 Census division $\times$ period interactions (there are 20 years of monthly data for 9 divisions). When the Census division $\times$ period interactions are included, all of the identifying information about minimum wage effects comes from within-division variation in minimum wages. An obvious concern is that this extensive set of controls captures a lot more than just the unobserved regional variation, and in particular may remove a good deal of valid identifying information on the effects of minimum wages; moreover, the identifying information that remains is not obviously better than the identifying information that has been removed. This is an issue that is never explored by ADR.

Figure 2 provides a picture of the identifying information that is available across and within Census divisions. The top panel plots the average quarterly minimum wage by division from 1990-2011, and the nine lower graphs plot the minimum wage by state, within division; all values are shown relative to the federal minimum. The graph shows that within some Census divisions there is virtually no variation relative to the federal minimum (e.g., East South Central), in some divisions there is more variation but little within-division identifying information (e.g., Mountain), and in other divisions there is both variation over time and across states (e.g., New England). Conversely, as the top panel shows, the across-division variation is rather extensive.

Thus, when ADR estimate their much more saturated model, the identifying information is substantially reduced and comes from a much more restricted set of comparisons. Before concluding that this more restricted identification provides more convincing evidence on the effects of minimum wages, a number of questions should be asked. To begin, what do we find if we estimate the models separately by 
Census division? In ADR's saturated specification the effect of the minimum wage (and all other controls) is constrained to be the same in each division. However, if we think that the patterns of unobserved shocks to divisions differ (or that the effects of the same observed shocks - like technological change - differ), why not also allow the effects of the observed variables to differ by division?

The results, which are reported in Table 3, reveal that the estimated effects of the minimum wage differ substantially across Census divisions, and - just as importantly - that our ability to obtain a precise estimate of the minimum wage effect varies substantially across divisions. In particular, for the New England, West North Central, West South Central, and Mountain divisions there are significant disemployment effects, with elasticities ranging from -0.15 to -0.64 , a rather large range. For three other divisions - East North Central, East South Central, and South Atlantic - the estimated effects are also negative, although these are not statistically significant, and the estimates for East South Central are implausibly large. Finally, for the Mid-Atlantic division the estimated elasticities are positive but insignificant, and for the Pacific divisions the estimates are near zero.

Looking at the standard errors, and having in mind as a plausible range of elasticities from prior evidence something like -0.1 to -0.3 or perhaps somewhat larger, it is clear that only three divisions New England, West North Central, and West South Central - yield sufficiently precise estimates to detect a statistically significant elasticity in this range. ${ }^{18}$ Thus, looking division-by-division, which in the spirit of ADR's study seems like the best way to control for spatial heterogeneity across Census divisions, yields one of two things - either precise estimates that point to disemployment effects, or estimates too imprecise to be informative. In and of itself, these results lead to a very different conclusion than the one reached by ADR.

Our finding that estimating the models separately by Census division often leads to very imprecise estimates naturally raises the question of whether, in controlling for spatial heterogeneity, it is really necessary to throw out information on other potential comparison states. The assumption that ADR

\footnotetext{
${ }^{18}$ This would not necessarily have been predicted from looking at the variation in Figure 2. On the one hand, New England and West North Central exhibit a fair amount of within-division variation in minimum wages. But West South Central has only one change, for Arkansas. In contrast, other divisions that display substantial variation such as South Atlantic - do not yield precise estimates. Much of the variation in the South Atlantic division is driven by Delaware and Washington, DC.
} 
make is that the states within a Census division are better controls for states where minimum wages increase than are states in other Census divisions. In particular, they argue that because minimum wage changes are correlated with economic shocks at the regional level, the models should include “...Census division-specific time effects, which sweeps out the variation across the nine divisions and thereby control for spatial heterogeneity in regional economic shocks ...” (p. 206). However, they do not test this hypothesis directly and, indeed, provide no convincing evidence that the counterfactual employment growth that comes from states in other Census divisions does not provide a good control. ${ }^{19}$ Moreover, there is considerable heterogeneity among states within Census divisions (e.g., Maryland vs. South Carolina, West Virginia vs. Florida, or Connecticut vs. Maine), and some divisions have many states and cover huge areas (e.g., the Mountain division), so the a priori argument for why the within-division states provide better controls is unclear. ${ }^{20}$

To address this shortcoming in ADR's analysis, we use two empirical approaches to determine which states are good controls for the states with minimum wage increases in any particular period. Our first approach uses the initial step of the Abadie et al. (2010) synthetic control approach to estimating treatment effects. This method can be applied to simple settings when a discrete treatment (like implementing a program) is applied to one unit (such as a geographic area) and not to others. The latter which are the potential control units (referred to as “donor” units) - are then sorted according to a matching estimator intended to measure the quality of each unit as a control. The choice of variables on which to match is subject to the choice of the researcher; most typical, perhaps, would be to match on prior values or percent changes (where there are level differences) in the outcome of interest. ${ }^{21}$

\footnotetext{
${ }^{19}$ ADR (and DLR) present some indirect evidence that their specification better captures spatial heterogeneity. However, as we show later in the paper, this indirect evidence is much less persuasive than the authors claim.

${ }^{20}$ For example, even if one accepted the notion that geographically-proximate states provide better controls, there is still a question of whether states within a Census division are better controls than closer states in other Census divisions.

${ }^{21}$ After ascertaining the match quality of each potential control unit, the method is then used to estimate the treatment effect by weighting control units based on quality of the match. In the present case, however, the focus is only on the identification of which states are better matches as controls, because in the minimum wage setting there is continuous variation in the treatment, and there are multiple increases, so it is unclear how to implement the second step.
} 
To draw a comparison with the literature on minimum wages, suppose we want to estimate the effect of a specific state minimum wage increase in this setting. If we had a time period when only one state raised its minimum wage, the standard panel data approach would use the other 49 states as controls. In contrast, the “case study” approach, typified by Card and Krueger (1994), would choose another state (or even a subset of that state) based on geographic contiguity. In this context, ADR's approach essentially restricts the set of control states to those in the same Census division. However, nothing in ADR's study establishes that states in the same division are better controls (just as nothing in the Card and Krueger study establishes that Pennsylvania is a good - let alone the best - control for New Jersey). The synthetic control approach provides us with empirical evidence on which states are the best control states. $^{22}$

We apply this approach to the CPS data used in the preceding analyses. We first define the set of treatment observations as state-quarter observations with minimum wage increases in that quarter and no minimum wage increase in the previous four quarters, yielding a set of 129 potential minimum wage treatments to analyze. For each of these treatments, we define a set of potential donor units (state-quarter observations) as states with no minimum wage increase in the same quarter and the succeeding three quarters, and no minimum wage increase in the previous four quarters. In these analyses, a variable is chosen on which to match over the four quarters prior to the treatment, ${ }^{23}$ and then the weights that the matching estimator assigns to each of these donor units are computed.

The validity of ADR's approach can be assessed by looking at how much of this weight is assigned to states in the same Census division. A finding that most of the estimation weight is on donor states in the same Census division as the treatment state would rationalize ADR's approach; states in

\footnotetext{
${ }^{22}$ Sabia et al. (2012) use the synthetic control approach to estimate the effects of the increase in the minimum wage in New York in 2004. In particular, they compare estimates using geographically proximate states to those that instead use control states picked by the synthetic control method. In their case the estimates are very similar, because the approach puts much of the weight on the geographically proximate states. However, they do not match on lagged values of the dependent variable. Also, in their analysis states outside of the Census division get substantial weight in the employment regression (Maryland and Ohio).

${ }^{23}$ In the matching process for each treatment case, the relative importance of each value of the matching variable over the four previous quarters is included in the optimization routine, but it can also be specified in advance. To obtain standardized results across all treatment cases and to economize on computational requirements, we treated lags one through four of the matching variable as equally important, although relaxing this restriction does not affect the results.
} 
other divisions would not match as well because those other regions have different prior trends.

Conversely, if only a little weight is put on state-quarter pairs in the same division, this would tell us that there is no good rationale to restrict (or even focus) attention on the states in the same Census division, either because spatial heterogeneity is not important, or if it is, because it is not specific to the Census divisions used by ADR. ${ }^{24}$

The synthetic control approach requires a choice of variables on which to match, and we used four different alternatives to implement the procedure. Three of these involve matching on forms of the dependent variable: the log of the teen employment-to-population ratio, as well as the one-quarter change and the four-quarter change in that variable, each of these defined over the four pre-treatment quarters. ${ }^{25}$ We also matched on the residuals from the standard panel data estimator for teen employment (Table 1, column (1)), again for the prior four quarters. This is not a standard type of variable on which to match, primarily because there typically is not a regression model underlying the application of the synthetic control approach; rather, the synthetic control estimator is typically used instead of a regression model. However, matching on the residuals is informative about the spatial heterogeneity arguments that ADR put forward, as their contention is that the residuals for states in the same Census division share common features that are correlated with minimum wage changes. Consequently, matching on the residuals provides information on whether the residuals for states in the same region share these commonalities and hence whether these states are good controls - or, in ADR's approach, should be isolated as the control states by including division $\times$ period dummy variables.

The results are summarized in Table 4. As noted, there are 129 unique treatments that are defined for this analysis. Of these, 50 have potential donors in the same Census division, covering six divisions. The key results are reported in columns (1)-(4); these are the weights from the matching process on states

\footnotetext{
${ }^{24}$ In some cases, there were no potential donor units in a division because all other states in the division had a minimum wage increase in the current quarter, the next three quarters, or the previous four; these cases were thrown out since no weight can be assigned to state-quarter pairs in the Census division if there are no donors in the division for that particular treatment. As a result, we look to see whether there is substantial weight on donor states in the same division only when there are such donor states, to avoid overstating the extent to which donor states come from other divisions.

${ }^{25}$ As explained in the notes to Table 4, when matching on the one- and four-quarter changes, treatment observations are lost at the beginning of the sample period.
} 
in the same division. With the exception of West North Central, these weights are generally well below one. In 14 out of the 24 cases they are below 0.25 , and in some cases they are quite close to zero. ${ }^{26}$ Columns (5)-(7) report on the average number of divisions and states in the donor pool, and the average number of states in the same division. One thing we see from these columns is that the low weight on states in the same division is not attributable to a small number of potential donor states from the same division. For example, East North Central has the second highest average number of potential donor states from the same division but weights close to zero, while West North Central has one of the lowest number of potential donor states from the same division but the highest weights.

These results provide striking evidence against ADR's choice to restrict the control states to those in the same Census division. For most Census divisions, states outside the Census division tend to be better controls for treatment observations, whether matched on regression residuals or on levels or growth rates of teen employment. In cases where most of the weight is on states outside the division, the conventional panel data estimator may provide more reliable estimates of minimum wage effects than the specification that includes division x period controls.

A second, more transparent method, which we term the "ranked prediction error" approach, is also used to address the question of which states are good controls for the states with minimum wage increases. The synthetic control approach finds a weighted average of the potential donor states to best match the treatment unit. The second method, instead, matches up the treatment unit to each potential donor unit one-by-one. For each of these potential controls, the root mean squared prediction errors (RMSPE) of the exact same matching variables used for the synthetic control approach are calculated for the donor unit relative to the treatment unit in the pre-treatment period (the four quarters prior to the MW change in the treatment unit). The analysis then asks whether the donors in the same division are better controls than the donors outside the division by comparing the RMSPEs for the same-division states with the RMSPEs for other states.

\footnotetext{
${ }^{26}$ Code in $\mathrm{R}$ was used to do these calculations. The software is available at http://www.mit.edu/ jhainm/synthpage.html (viewed July 30, 2012).
} 
Some notation helps to clarify the method and the difference between the two approaches. Denote a specific treatment unit by $T,{ }^{27}$ the potential donors in the same division $\mathrm{D}^{\mathrm{s}}, \ldots, \mathrm{D}_{\mathrm{J}}^{\mathrm{s}}$, and the potential donors in other divisions $\mathrm{D}^{0}{ }_{1}, \ldots, \mathrm{D}^{\circ}{ }_{\mathrm{K}}$. The synthetic control approach finds a weight for each donor, $w_{1}^{\mathrm{s}}, \ldots, w_{\mathrm{J}}^{\mathrm{s}}$ and $w_{1}^{0}, \ldots, w_{\mathrm{K}}^{\mathrm{o}}$, to best match the treatment unit during the pre-treatment period, using an RMSPE criterion. What was done before, then, was to sum up the weights for the donor states in the same division, $W^{s}=\Sigma_{\mathrm{j}} w_{\mathrm{j}}^{\mathrm{s}}$, and ask whether this weight was large.

In the ranked prediction error approach, we calculate the RSMPE separately for each potential donor, for the same-division and other-division donor states respectively (denoted $r_{\mathrm{j}}^{\mathrm{s}}, \mathrm{j}=1, \ldots, \mathrm{J}$, or $r_{\mathrm{k}}^{\mathrm{o}}$, $\mathrm{k}$ $=1, \ldots, \mathrm{K})$. These $r$ 's are then pooled, and ordered based on how well they match the treatment unit according to an RMSPE criterion. Finally, a percentile in this ranking is assigned to each donor unit, denoted $P_{\mathrm{m}}, \mathrm{m}=1, \ldots,(\mathrm{J}+\mathrm{K})$, where the highest rank is given to the donor with lowest $r{ }^{28}$

The percentile assigned to a donor state is defined as the percentage of donor states with a higher RMSPE - i.e., a worse match. Thus, a percentile of 100 (or near 100 with a smaller number of states) would imply that a particular donor unit provides the best match. A percentile near zero would imply that it provides the worst match. And a percentile near 50 would suggest that it provides about as good a match as a randomly chosen control unit.

If $\mathrm{ADR}$ are correct that same-division states provide better controls than states in other divisions, then the percentile ranking should be higher, on average, for states in the same division as a treatment unit than for states in other divisions. To test this, the percentiles for same-division states are collected after doing this analysis for every possible treatment unit and the associated matching variables (exactly as in the synthetic control analysis), and histograms for these percentiles are constructed to see if the samedivision states are clustered at higher percentiles than would be expected if these states were, on average, no better or worse controls than other states (or, equivalently, if the distributions of the percentiles appear approximately uniform).

\footnotetext{
${ }^{27}$ The treatment unit is a particular state in a particular quarter; the time subscript is omitted.

${ }^{28}$ For example, if there are 50 donor units, then the unit with the lowest RMSPE gets a rank of 50. The Weibull rule is used to convert ranks to percentiles. With $\mathrm{N}$ units, the percentile is $(100 \times$ rank $) /(\mathrm{N}+1)$.
} 
To help explain, Figure 3 displays an example of the first step of this process for one treatment unit - California in 2001:Q1. The potential same-division donor states are Alaska, Hawaii, and Oregon; Washington is also in the Pacific division but had a minimum wage increase in the same quarter. For each of the four matching variables, the corresponding figure is the histogram of RMSPEs for all potential donor states, with the three same-division states highlighted with the thin vertical lines that extend to the top of the box. As the figure reveals, states within the same division can provide quite good matches, with low RMSPEs relative to other states (e.g., Hawaii in the lower-right panel), or they can provide quite bad matches, with relatively high RMSPEs (e.g., Hawaii in the upper-left panel).

Figure 4 then presents the analysis aggregating across all of the treatment units, plotting the histogram for the percentiles in the RMSPE distribution for each same-division state that ever appears as a potential donor in this analysis. The figure indicates no tendency of these percentiles to be clustered towards the upper end of the distribution, and in fact the medians are around 50. The implication is that the same-division control states are, on average, no better than the control states from other divisions, contrary to ADR's identification strategy.

We also examined the medians of these percentiles for each of the Census divisions. The only division where other states in that division consistently stand out as generally providing the best controls - in the sense that the percentile rankings are above the median - is the West North Central region. Looking back at Table 4, notice that the synthetic control approach indicated a high weight on samedivision states only for this division. Thus, the two analyses lead to a qualitatively similar conclusion. Both raise doubts about the validity of ADR's restriction that identifying information be confined to states in the same division, with one notable exception - the West North Central division.

Finally, a comparison of the estimates in Table 3 with the results from the synthetic control or ranked prediction error approach is instructive. Both approaches show that the only Census division for which there is a strong indication that most of the control states should come from within the division is West North Central. Table 3 shows that when minimum wage effects are estimated for this division in isolation, there is statistically significant evidence of a negative employment effect of minimum wages, 
with an estimated elasticity -0.19 - very much in line with much of the existing evidence on minimum wages.

Furthermore, Table 4 also indicates that New England and the Pacific regions assign nonnegligible weight to states in the same region. Of the two, the estimates in Table 3 for New England are precise, as noted above, and these estimates also point to negative employment effects (with a larger disemployment effect). In contrast, Table 4 indicates that especially for the matching on residuals which seems most pertinent to ADR's argument - states in the same division get essentially no weight for the Middle Atlantic and East North Central. These are two cases that, in Table 3, do not provide any evidence of disemployment effects. Thus, while this analysis does not pin down one "best" estimator, it does indicate that (a) in most cases, there is little rationale for ADR's choice to focus only on the withindivision variation to identify minimum wage effects; and (b) when there is a good rationale for doing this, the evidence shows negative and statistically significant effects of minimum wages on teen employment, with elasticities that are in or near the -0.1 to -0.2 range.

Dube et al. (2010)

As noted earlier, Dube et al. (DLR) focus on restaurant employment with county-level QCEW data from 1990-2006. They show that the standard panel data model with county and period fixed effects yields negative employment effects, with elasticities in the conventional range, whereas these effects become small and insignificant when either state-specific linear time trends or Census division $\times$ quarter interactions (or both) are added. As noted above, the inclusion of these additional controls is problematic.

However, the main focus of this paper is on a research design based on cross-border county pairs. When DLR include unique dummy variables for cross-border contiguous county pairs interacted with period, they identify the effect of minimum wages from differences in employment changes in these paired counties on either side of a state border - using the within-county-pair variation in the same way that including division $\times$ period dummy variables in the specifications in ADR relies on the withinCensus division variation. Given that this identification strategy is the key contribution of this paper, we focus on their cross-border analysis of the effects of minimum wages on restaurant employment rather than on their analyses that more closely parallel ADR. 
The key estimates from this approach are reported in Table 5, replicating the results in DLR (Table 2, specifications 5 and 6); the estimates are nearly identical to theirs. The first two columns use the balanced panel of the subset of counties in the contiguous border county-pair analysis, but include only county and period (quarter) fixed effects. As in DLR, two specifications are reported - with and without a control for total private-sector employment. The estimated minimum wage effects on restaurant employment are negative and in the old "consensus range,” with the first significant at the ten-percent level. In columns (3) and (4), county-pair $\times$ period interactions are added to replicate DLR's method of controlling for spatial heterogeneity. As the table shows, the estimated minimum wage effects are slightly positive and statistically insignificant.

Prior to getting to our main line of inquiry regarding this paper, it is useful to know the state borders along which DLR identify minimum wage effects. In fact, DLR substantially overstate the number of cross-border county pairs that are used to identify the effects of minimum wages in their approach. Their Figure 2 claims to show all the state borders - and counties along them - that are used in their analysis. This figure is replicated in Panel A of Figure 5, and shows 81 distinct state border pairs. However, many of the borders highlighted in this figure are for pairs of states that did not have a minimum wage higher than the federal minimum during their sample period. Panel B shows the corrected figure, which clearly includes far fewer state borders. For example, while the top panel suggests that there is identifying information along the Michigan, Indiana, and Ohio borders, the bottom panel shows that there is in fact no minimum wage variation along these borders. All told, there are only 48 distinct state border pairs with identifying information. ${ }^{29}$

However, the main question concerns the underlying assumption in DLR's identification strategy - that the cross-border contiguous county in the bordering state that did not raise its minimum wage is the

\footnotetext{
${ }^{29}$ Note that Panel B has the counties on the North and South Dakota border shaded, whereas Panel A does not. There was a higher minimum wage in North Dakota (by five cents) in the first three months of 1990, so this is one border that DLR missed. There is also another slight discrepancy. DLR's data includes a higher minimum wage in Maryland in the first six months of 2006 - \$6.15, instead of the \$5.15 federal minimum wage that actually prevailed. This correction would eliminate two additional state border pairs (Maryland's border with Virginia and West Virginia). However, in this paper we use their original data and making this correction to the data did not materially change the results. Finally, note that to maintain consistency with DLR's analysis, we use the balanced sample of counties with data in all periods. That restriction drops some counties along the borders shown in the figures.
} 
best control for the county in the state that did raise its minimum. ${ }^{30}$ As they point out, this has close parallels to the type of analysis in Card and Krueger (1994), who studied the effects of the 1992 minimum wage increase in New Jersey by comparing employment changes in the fast food industry in that state to areas in Pennsylvania - where the minimum wage stayed fixed - on or near the border with New Jersey.

There is some intuitive appeal to the idea that cross-border counties are good controls because of their geographic proximity. And we might expect that, on a priori grounds, the case for using contiguous counties as controls is stronger than for using states in the same Census division (as in ADR). ${ }^{31}$

Nonetheless, this assumption should be tested - geographic proximity does not necessarily imply that cross-border counties experience the same shocks. ${ }^{32}$ Is there evidence for DLR's assumption that crossborder contiguous counties provide appropriate control groups? As before, we address the question of the quality of cross-border contiguous counties as controls using the synthetic control matching estimator this time to calculate the weight that the matching puts on the contiguous cross-border counties relative to the weight it puts on other potential control counties.

The analysis exactly parallels the state-level analysis. Potential donors to the control group are all counties in the states that were identified as potential donors in the previous analysis. ${ }^{33}$ The estimator is then implemented, and the weights put on the cross-border control counties that DLR actually use are computed. The criteria for defining treatments and controls are the same as before, but now done at the county level. In particular, the set of treatment counties are border counties with a minimum wage increase and where there was no minimum wage increase in the previous four quarters. Potential donor units are county-quarter observations with no minimum wage increase in the same quarter and the

\footnotetext{
${ }^{30}$ For some treatment counties, there are more than one cross-border contiguous county.

${ }^{31}$ Note, however, that cross-border contiguous counties would not be good controls if they were affected by the minimum wage on the other side of the border. For example, if disemployment effects in the treated county lead workers to cross the state border for jobs, then the disemployment effects would be overstated. Conversely, if the minimum wage increase induces workers from the cross-border control county to queue for jobs in the treated county (as in Mincer, 1976), then employment in the control county can fall along with employment in the treatment county.

${ }^{32}$ Addison et al. (2009), who do a similar analysis, acknowledge this issue. Although, they still use this method to estimate minimum wage effects, they give an example of a cross-border county match that is quite bad, with a 3.5\% unemployment rate for one treatment county and a 7.7\% unemployment rate for the contiguous cross-border county, and they suggest that "such examples of poor matches across state borders could be rather common" (p. 406).

${ }^{33}$ The set of potential donors is restricted to the counties in the balanced sample of counties (with non-missing employment data) that DLR use.
} 
succeeding three quarters, and similarly no minimum wage increase in the previous four quarters. Two different analyses are done. The first includes all potential donor counties. In the second analysis, we restrict the set of donor counties on which the synthetic control calculation has to match. In particular, we first calculate, for each treatment and the potential donor counties, the RMSPE of each donor county for the four quarters prior to the minimum wage increase. We then use the 50 donor counties with the lowest RMSPE as potential donors, adding in DLR's contiguous cross-border counties if they are not already in this set of 50 .

The match is done on the same types of variables as before defined over the four previous quarters: regression residuals (from a regression of the log of the ratio of restaurant employment to county population on the log of the minimum wage and state and period (quarter) dummy variables); the log of county restaurant employment relative to county population; and the one-quarter and four-quarter differences in logs of restaurant employment relative to county population. As before, in some cases there were no potential contiguous cross-border donor units for a county, and these cases are thrown out.

The results are reported in Table 6, and the analysis reveals that the weight assigned to the crossborder contiguous counties as controls - the only controls DLR use - is very small. In Panel A, where there are typically just over 50 possible controls for each treatment, the weight on the cross-border contiguous counties is, on average, 0.033 in column (1), and of a similar or smaller magnitude in the other columns. (As for ADR, we view the results for the regression residuals as most pertinent to the critique in DLR.) Given that there are on average 1.7 cross-border contiguous counties in the donor pool, and the donor pool on average includes 51.3 counties, ${ }^{34}$ if we put equal weight on each county in the donor pool that weight would be 0.033 (1.7/51.3). In other words, within these donor pools the control counties that DLR use appear no better than a random draw. The same is true in Panel B. In column (1) the weight on DLR's control counties is 0.007 , only slightly above the share of these latter counties in the potential donor pool (0.005).

\footnotetext{
${ }^{34}$ Note that the latter number need not be 51.7 (i.e., $50+1.7$ ), because the contiguous cross-border counties are sometimes among the 50 counties with the lowest RMSPE.
} 
The table also shows the percentiles of the distribution of weights. The distribution is highly skewed. For example, in column (1) of Panel A, the median is only 0.008, compared with the mean of 0.033, and the $75^{\text {th }}$ percentile is below the mean (0.029). In Panel B (also column (1)), the $90^{\text {th }}$ percentile is below 0.01 . Table 6 indicates quite clearly that for almost all counties, the cross-border county is a poor match - no better than a county chosen at random from the list of all potential comparison counties. Given this evidence, it seems difficult to argue that throwing out all the information on other potential comparison counties, as DLR do, is preferable to using the standard panel data estimator.

Because there is some a priori appeal to the idea that cross-border counties are useful controls (even if the evidence to this point does not bear this out), we also looked more closely at cross-border counties for MSAs that straddle two states, to see whether within these more integrated labor markets the cross-border counties were better controls. Out of our 121 unique minimum wage treatments considered in Table 6, 33 have cross-border controls that are in other states but in the same MSA. ${ }^{35}$ We compared the weights we calculated for the cross-border counties in this subsample to the weights implied by a randomly chosen county. Specifically, if there was only one cross-border county in the MSA we compared the weight on that county to $1 /$ (number of potential donors), and if there was more than one cross-border county we averaged the weight across these counties and did the same comparison. In only four cases out of 128 possible matches (for counties and matching variables) ${ }^{36}$ was there a much higher weight for the cross-border county; three of these were in the New York-Newark-Edison, NY-NJ-PA MSA, and the other was in the Lewiston, ID-WA MSA. In seven other cases the average weight for the cross-border county was higher, but trivially so; the within-MSA weights were in the 0.001-0.019 range, and the differences relative to a randomly chosen county were less than 0.001 . Thus, even within MSAs there is no evidence that cross-border counties provide better controls.

We also used the ranked prediction error approach to assess whether contiguous cross-border counties are better controls than other counties. The method is the same as before, but now examines the percentiles for the matched contiguous cross-border counties (analogous to the previous examination of

${ }^{35}$ Examples are Nez Perce County, ID, in the Lewiston, ID-WA MSA, and Westchester County, NY, in the New York-Newark-Edison, NY-NJ-PA MSA.

${ }^{36}$ There are 33 counties, in most cases with four possible matching variables. 
same-division states). Figure 6 shows the percentiles for these matched counties. There is perhaps a slight tendency for these percentiles to be clustered above 50, but, in general, the histograms seem fairly close to uniform. Again, there is little in the data to support the assumption made by DLR that the contiguous cross-border counties are the appropriate controls.

One might argue that it is not surprising that in our two types of analyses the contiguous crossborder counties get so little weight or fail to stand out as the best control areas. After all, as shown in column (5) in Panel B of Table 6, there is typically a very large number of potential donor counties for any one county's minimum wage increase. But that is precisely the point: With the large set of potential donor counties, why throw away so much potential identifying information without assessing which counties are in fact the best controls?

Is there other evidence that justifies the approach in ADR and DLR?

ADR and DLR present two analyses that are intended to show that their identification strategy is valid and that the more conventional panel data approach, which uses a much broader set of controls (states or counties), leads to spurious evidence of negative minimum wage effects because of spatial heterogeneity. The first is an analysis of employment changes prior to the implementation of minimum wages, and the second is pitched as a falsification test showing that county employment appears to respond to cross-border minimum wage changes.

In the first analysis, ADR estimate dynamic models for employment and earnings with long leads and lags, and then present figures showing cumulative effects at these leads and lags based on the coefficients from these models. For example, in their Figure 2, ADR plot the cumulative effects from leads of two years to lags of four years for the standard panel data specification with fixed state and period effects, as well as for the specification that adds both the state-specific linear time trends and the Census division $\times$ interactions. The replication of their graphs for employment effects appear in the upper-left and upper-right panels of Figure 7. According to ADR, the evidence of leading effects in the upper-left panel, in comparison with the evidence in the upper-right panel, provides "strong evidence against the model without controls for heterogeneity across states ...” (p. 220). 
However, this evidence is both overstated and misleading. First, note that the figure also suggests that the inclusion of state-specific linear time trends and the division $\times$ period interactions produces fairly substantial positive estimates of the effect of the minimum wage on teen employment - with elasticities of about 0.2 - three to four years after the minimum wage increase. Although ADR do not remark on this, it seems unlikely that those estimates represent the real effects of minimum wages and hence they could be viewed as providing evidence against the model that includes those controls.

Second, although the regression estimates for their main analyses are based on quarterly data, the graphs they show in their Figure 2 (replicated here in the top row of Figure 7) are generated from a model specified with leads and lags on an annual basis. The bottom two panels of the figure show the graphs from a less constrained model that specifies the leads and lags at a quarterly frequency. Not surprisingly, the plots are noisier. However, the quarterly graphs appear to show three things: (1) they do not give a clear indication of any kind of pre-trend in the standard panel data model; (2) they point to negative employment effects in the two years after the minimum wage increase that look quite distinct from anything occurring in the data prior to the minimum wage increase; and (3) they show significant positive employment effects (with elasticities in the 0.4 to 0.5 range) more than three years after the minimum wage increase in the model with state-specific linear trends and division $\times$ period interactions, which again could be construed as evidence against that model.

DLR also present evidence suggesting that the inclusion of state-specific linear trends and Census division $\times$ period interactions in panel-data models eliminates spurious negative estimates of the effects of minimum wage for periods without a minimum wage increase. This analysis is captured succinctly in their Table 3, which - for the model with just county and period fixed effects - reports the "effect” three years prior to the minimum wage increase, one year prior, and the "pre-trend" based on the difference between the cumulative effects at these two points. ${ }^{37}$ The replication of their results is reported in column (1) of Table 7; again, the results are nearly identical to theirs. The evidence points to a fairly large

\footnotetext{
${ }^{37}$ These models include a contemporaneous effect of the minimum wage, two leads at three years (12 quarters) and one year (4 quarters), but no lagged minimum wage effects. The results discussed below for this specification and variants thereof are very similar if the intervening semi-annual leads (which they include in the specification on which the figure discussed below is based) are included as well.
} 
cumulative negative "effect” at a four-quarter lead, and also a negative trend 12 quarters to four quarters prior to the minimum wage increase; both estimates are significant at the ten-percent level. These same results, in somewhat more detail, are reported in their Figure 4, which shows a growing cumulative negative effect up to the minimum wage increase, although this cumulative leading “effect” is never statistically significant. This is replicated in the upper-left panel of Figure 8.

Note, however, that their figure also shows a positive cumulative leading effect for the model with state-specific linear trends and division $\times$ period interactions, and in this case the cumulative effect is sometimes statistically significant; see the upper-middle panel of Figure 8, which also replicates their Figure 4. Not only do DLR fail to remark on this result; they essentially deny it, claiming (on p. 956) that this specification shows "relatively stable coefficients for the leads centered around 0.”38

DLR also omit the estimates of this specification from their Table 3, which they use to criticize the "canonical” panel data model as showing a pre-existing negative trend. However, we computed the corresponding estimates for the model including the state-specific linear trends and the division $\times$ period interactions (their specification 3) and report the results in column (2) of Table 7. These estimates show a significant positive "pre-trend" of the same magnitude as the negative pre-trend obtained from the standard model. And since negative anticipatory effects of a minimum wage are at least in principle plausible (as acknowledged by ADR, p. 220), one might argue that the positive pre-trend raises particular doubts about the specification with state-specific trends and division $\times$ period interactions.

Moreover, there is no obvious rationale for focusing only on the pre-trend calculated between the $4^{\text {th }}$ and the $12^{\text {th }}$ quarters. If the results were robust to which interval was used, it would be of little consequence. However, Panel A of Table 8, which retains the specification with 12-quarter leads, but computes the pre-trend between the $2^{\text {nd }}, 6^{\text {th }}, 8^{\text {th }}$, and $10^{\text {th }}$ quarters as well, shows that this is not the case. As columns (1) and (2) show, it is only for the $4^{\text {th }}$-to- $12^{\text {th }}$ quarter interval that the “canonical” or standard panel-data model (column (1)) generates a statistically significant pre-trend, and for many of the other intervals it is quite small. In contrast, for the model with county and period fixed effects, state-specific

\footnotetext{
${ }^{38}$ To be precise, this quote refers to a different specification (specification 6), but they then say that the results in question are similar: "Intermediate specifications ... with coarser controls for heterogeneity in employment show similar results to the local specification (6)” (p. 956).
} 
linear trends, and division $\times$ period interactions, the pre-trend is significant and positive in every case. Column (3) shows the similar estimates for the contiguous border county-pair sample. These estimates are all statistically insignificant; however, the standard errors are large, and in some cases the coefficient estimates are of roughly the same absolute magnitude as the estimates in column (1).

As Panel B of Table 8 shows, the evidence for their claim is even weaker in regression models that correspond to their Figure 4 but that include leads only up to 8 quarters. In this case, the canonical model shows no evidence of pre-trends, with estimates that are small and statistically insignificant. However, for the model with county and period fixed effects, state-specific linear trends, and division $\times$ period interactions, there is again robust evidence of a positive pre-trend. And for the contiguous border county-pair sample, the point estimates in two of three cases are large and positive, although insignificant given the very large standard errors.

The table highlights in bold and italics the two estimates reported in DLR's Table 3 for this specification. ${ }^{39}$ It is quite clear that the estimates DLR emphasized are the ones that most strongly make their case, and that there are many more equally plausible analyses of the issue of pre-trends that produce much weaker evidence, and indeed sometimes support the opposite conclusion.

Finally, Figure 4 in DLR - replicated in the top three panels of Figure 8 - parallels the figure in ADR by using data at a smoother semi-annual frequency than the quarterly frequency used in all their model estimates. As shown in Panel B of Figure 8, when the figures are replicated using the data on a quarterly basis, the figure for specification 1 is much less suggestive of any kind of pre-treatment trend. ${ }^{40}$ In fact, the only pronounced negative estimate is one quarter before the treatment. In contrast, the figure for specification 3 still shows a pronounced upward trend prior to the treatment. And, to us at least, it is not obvious that the pre-trend apparent for specification 6 - DLR's preferred contiguous border countypair analysis - is less problematic. It is true that the estimates are much less precise, as indicated by the wider confidence intervals. But there is a noticeable increase in employment in the two quarters

\footnotetext{
39 There are alternative specifications with a control for private-sector employment added, but the results are similar. ${ }^{40}$ How one views these graphs is partly subjective. But this interpretation appears to be more accurate than DLR's claim that "Using leads and lags for every quarter, as opposed to every other quarter, produces virtually identical results” (p. 956, footnote 24).
} 
preceding the minimum wage increase, and the decline subsequent to that is of roughly the same order of magnitude as the decline in the figure for specification 1.

In a second analysis, DLR present results from what they refer to as a falsification test, which they argue supports their view that spatial heterogeneity is responsible for the negative effects of minimum wages on employment found in conventional panel data estimates (p. 958). In particular, they define a narrow sample of all border counties where the minimum wage was never above the federal minimum wage in the sample period, and then estimate the standard panel data specification (with county and period fixed effects) for this sample, substituting the cross-border counties' minimum wages. When they do this, their estimated “placebo" minimum wage effect is negative, albeit smaller than its standard error, and it is about 60 percent of the estimated minimum wage effect for the counties bordering the placebo sample but using their actual minimum wages. ${ }^{41}$ These estimates are replicated in column (1) of Table 9.

However, DLR do not have a valid falsification test. For most county pair-quarter observations in the sample they use (96 percent), both the cross-border minimum wage and the own-county minimum wage are the same - equal to the federal minimum wage. Thus, in most cases the placebo minimum wage assigned to the county is equal to the actual minimum wage prevailing in the county, which of course can affect employment. ${ }^{42}$ In other words, DLR assume that the null hypothesis of no spatial heterogeneity implies that the effect of the placebo minimum wage is zero, and then reject this null because their estimated placebo minimum wage effect is negative. But because the "placebo" minimum wage they use is often the same as the actual minimum wage, we would expect a negative minimum wage effect in their placebo analysis even if there is no spatial heterogeneity - invalidating their falsification test.

Confirming this problem, we do not find a placebo effect when the sample used for DLR's falsification test is modified to avoid having a contaminated placebo sample. Specifically, we restrict the sample to observations after the federal minimum wage increase in 1997, so that there is no federal

\footnotetext{
${ }^{41}$ See their Appendix B for further information on how they implemented their falsification test.

${ }^{42}$ Note that the effect of federal minimum wage variation is still identified in their placebo sample when county and period fixed effects are included as long as the federal minimum wage is not binding in some states. The minimum wage change induced by federal variation will vary across placebo counties depending on the level of the state minimum wage in the cross-border county.
} 
minimum wage variation in the placebo counties that is captured by the counties matched to them. ${ }^{43}$ As shown in column (2) of Table 9, in this case the estimated minimum wage effect in what DLR term the “actual minimum wage” sample is large, negative, and statistically significant, while the estimate for the placebo sample is much smaller and statistically insignificant. ${ }^{44}$ In this placebo sample, there are still many counties paired with cross-border counties that have the same federal minimum wage (although now it does not vary); only 7 percent of the county pair-quarters have a minimum wage difference. It is possible to further restrict attention to an even more informative placebo sample by focusing on county pairs where there is at least one minimum wage difference in this sample period between the true minimum wage in the placebo county and the cross-border minimum wage that is used in the falsification test; after all, it is this variation that is informative about their falsification test. As shown in column (3), in this case the estimated minimum wage effect in the placebo sample falls to zero, while the estimated minimum wage effect in the actual minimum wage sample is little changed. These estimates provide yet additional evidence refuting DLR’s claim that spatial heterogeneity generates spurious evidence of disemployment effects of minimum wages. ${ }^{45}$

\section{$\underline{\text { IV. Conclusions }}$}

Throughout the long-running debate about the employment effects of minimum wages, the empirical evidence has focused on similar questions: How does a minimum wage affect employment?

\footnotetext{
${ }^{43}$ Their sample ends before the most recent round of federal increases beginning in 2007. In this exercise, we use data beginning in 1998:Q3, one year after the last federal minimum wage increase, to avoid lagged effects of federal minimum wages. But the results were very similar if the sample starts in 1997:Q4, the first quarter after the last federal increase.

${ }^{44}$ The standard errors in both samples are a good deal smaller, likely because there is much more state minimum wage variation in the latter part of the sample.

${ }^{45}$ Additional evidence in Thompson suggests that ADR's and DLR's conclusion that spatial heterogeneity generates spurious evidence of disemployment effects is wrong. His analysis is at the county level, because there is considerable within-state heterogeneity in wage levels and local labor market conditions, and because, he argues, counties better represent labor markets for teens than do entire states given constraints that keep teens close to where they live. Thompson finds substantial negative effects of federal minimum wage increases in the low-earnings (or high-impact) counties. This analysis considers the types of factors that DLR and ADR suggest can lead to spurious evidence of disemployment effects of minimum wages. First, by identifying the effects from differences between counties with low versus high teen earnings, it controls for state-specific changes or trends that could be correlated with minimum wage changes. Moreover, because the minimum wage variation comes from federal legislation, and the identification comes from cross-county variation within states, any endogeneity of state minimum wages is unlikely to be a confounding influence. Second, in a "placebo test," Thompson uses the same methods to estimate minimum wage effects two years later when the federal minimum wage did not change. He finds no effect, which suggests that differential trends for low- and high-earnings counties do not drive the results.
} 
Which workers are affected? And how do we ensure that we are getting a valid comparison that isolates the effect of the minimum wage?

Given the ongoing ebb and flow of this debate, it would have been shortsighted to think that the 2008 book that two of us wrote (Neumark and Wascher, 2008), despite surveying a massive amount of evidence, would have settled the issue. And indeed it has not. In particular, echoing long-standing concerns in the minimum wage literature, Dube et al. (2010) and Allegretto et al. (2011) attempt to construct better counterfactuals for estimating how minimum wages affect employment. When they narrow the source of identifying variation - looking either at deviations around state-specific linear trends or at within-region or within-county-pair variation - they find no effects of minimum wages on employment, rather than negative effects. Based on this evidence, they argue that the negative employment effects for low-skilled workers found in the literature are spurious, and generated by other differences across geographic areas that were not adequately controlled for by researchers.

Our analysis suggests, however, that their methods are flawed and lead to incorrect conclusions. In particular, neither study makes a compelling argument that its methods isolate more reliable identifying information (i.e., a better counterfactual). In one case - the issue of state-specific trends - we explicitly demonstrate the problem with their methods and show how more appropriate ways of controlling for unobserved trends that affect teen employment lead to evidence of disemployment effects that is similar to that reported in past studies. In the other case - identifying minimum wage effects from the variation within Census divisions or, even more narrowly, within contiguous cross-border county pairs - we show that the exclusion of other regions or counties as potential controls is not supported by the data.

We think the central question to ask is whether, out of their concern for avoiding minimum wage variation that is potentially confounded with other sources of employment change, ADR and DLR have thrown out so much useful and potentially valid identifying information that their estimates are uninformative or invalid. That is, have they thrown out the "baby" along with - or worse yet, instead of the contaminated "bathwater"? Our analysis suggests they have. Moreover, despite the claims made by ADR and DLR, the evidence that their approaches provide more compelling identifying information than the standard panel data estimates that they criticize is weak or non-existent. 
In addition, when the identifying variation they use is supported by the data, the evidence is consistent with past findings of disemployment effects. Thus, our analysis substantially undermines the strong conclusions that ADR and DLR draw - that there are "no detectable employment losses from the kind of minimum wage increases we have seen in the United States” (DLR, 2010, p. 962), and that "Interpretations of the quality and nature of the evidence in the existing minimum wage literature ..., must be revised substantially” (ADR, 2011, p. 238).

Can one come up with a dataset and an econometric specification of the effects of minimum wages on teen and low-skilled employment that does not yield disemployment effects? As in the earlier literature, the answer is yes. But prior to concluding that one has overturned a literature based on a vast number of studies, one has to make a much stronger case that the data and methods that yield this answer are more believable than the established research literature, and convincingly demonstrate why the studies in that literature generated misleading evidence. Our analysis indicates that the studies by Allegretto et al. (2011) and Dube et al. (2010) fail to meet these standards. Based on this evidence, we continue to believe that the empirical evidence indicates that minimum wages pose a tradeoff of higher wages for some against job losses for others, and that policymakers need to bear this tradeoff in mind when making decisions about increasing the minimum wage.

We also believe that there are more general lessons to be learned from this paper. Although the results in the paper focus on the evidence on the employment effects of minimum wages, a similar set of issues carries over to the analysis of essentially any kind of policy with regional variation that might be studied with panel data on these regions over time. When doing these kinds of panel data studies, researchers often make the same choices as ADR and DLR - such as including state-specific linear time trends, or narrowing the scope of the geographic areas used for controls by either restricting the sample or estimating a more saturated model that reduces the identifying information to variation within a smaller region. Our evidence suggests that these kinds of analyses, even if well motivated, can deliver misleading evidence of either the presence or absence of effects. We do not advocate ignoring the potential biases introduced by differences in the regions where policies are enacted. We do, however, advocate using the data to explore more fully what specifications provide the most reliable counterfactuals, and we discuss 
some methods for doing this. After all, in other contexts - such as instrumental variables estimation - we generally ask hard questions about the validity of the identifying assumptions used in those analyses.

In particular, if these kinds of sensitivity analyses deliver robust results that are insensitive to detrending or narrowing of control areas, then they can clearly bolster the evidence. If, however, they point to different evidence, then the researcher has to seriously explore which analysis is most convincing. In the case of removing long-term trends from panel data over time, we have suggested methods that increase the likelihood that business cycle movements are not confounded with long-term trends. And in the case of restricting the set of control areas, we have shown how to obtain evidence on which areas are better controls. We believe these kinds of approaches - and others more appropriate to different types of analyses - should be incorporated into what can otherwise be a somewhat blind approach to sensitivity analysis. And we would suggest that these kinds of approaches are particularly imperative in cases where a particular sensitivity analysis is claimed to overturn a large body of existing evidence. 


\section{$\underline{\text { References }}$}

Aaronson, Daniel, Park, Kyung-Hong, and Daniel Sullivan. 2007. "Explaining the Decline in Teen Labor Force Participation.” Chicago Fed Letter, Number 234, January, The Federal Reserve Bank of Chicago.

Abadie, Alberto, Alexis Diamond, and Jens Hainmueller. 2011. "Comparative Politics and the Synthetic Control Method.” Working Paper No. 2011-25, MIT Political Science Department.

Abadie, Alberto, Alexis Diamond, and Jens Hainmueller. 2010. "Synthetic Control Methods for Comparative Case Studies: Estimating the Effect of California's Tobacco Control Program.” Journal of the American Statistical Association, Vol. 105, No. 490, June, pp. 493-505.

Addison, John T., McKinley L. Blackburn, and Chad D. Cotti. “The Effect of Minimum Wages on Labour Market Outcomes: County-Level Estimates from the Restaurant-and-Bar Sector.” Forthcoming in British Journal of Industrial Relations.

Addison, John T., McKinley L. Blackburn, and Chad D. Cotti. 2011. "Minimum Wage Increases in a Soft U.S. Economy.” Economic Series No. 273, Institute for Advanced Studies, Vienna.

Addison, John T., McKinley L. Blackburn, and Chad D. Cotti. 2009. “Do Minimum Wages Raise Employment? Evidence from the U.S. Retail-Trade Sector.” Labour Economics, Vol. 16, No. 4, August, pp. 397-408.

Allegretto, Sylvia A., Arindrajit Dube, and Michael Reich. 2011. "Do Minimum Wages Really Reduce Teen Employment? Accounting for Heterogeneity and Selectivity in State Panel Data.” Industrial Relations, Vol. 50, No. 2, April, pp. 205-240.

Baskaya, Yusuf Soner, and Yona Rubinstein. 2011. "Using Federal Minimum Wage Effects to Identify the Impact of Minimum Wages on Employment and Earnings Across U.S. States.” Unpublished paper, Central Bank of Turkey.

Brown, Charles, Charles Gilroy, and Andrew Kohen. 1982. "The Effect of the Minimum Wage on Employment and Unemployment,” Journal of Economic Literature, Vol. 20, No. 2, June, pp. 487-528.

Card, David. 1992a. "Using Regional Variation in Wages to Measure the Effects of the Federal Minimum Wage.” Industrial and Labor Relations Review, Vol. 46, No. 1, October, pp. 22-37.

Card, David. 1992b. “Do Minimum Wages Reduce Employment? A Case Study of California, 19871989.” Industrial and Labor Relations Review, Vol. 46, No. 1, October, pp. 38-54.

Card, David, and Alan B. Krueger. 1994. "Minimum Wages and Employment: A Case Study of the FastFood Industry in New Jersey and Pennsylvania.” American Economic Review, Vol. 84, No. 4, September, pp. 772-93.

Cogley, Timothy, and James M. Nason. 1995. "Effects of the Hodrick-Prescott Filter on Trend and Difference Stationary Time Series: Implications for Business Cycle Research.” Journal of Economic Dynamics and Control, Vol. 19, Nos. 1-2, January-February, pp. 253-278.

Congressional Budget Office. 2004. "What Is Happening to Youth Employment Rates?” Available at http://cbo.gov/sites/default/files/cbofiles/ftpdocs/60xx/doc6017/11-18-youthemployment.pdf (viewed March 12, 2011).

Douty, H. M. 1960. “Some Effects of the \$1.00 Minimum Wage in the United States.” Economica, Vol. 27, No. 196, May, pp. 137-47.

Dube, Arindrajit, T. William Lester, and Michael Reich. 2010. "Minimum Wage Effects Across State Borders: Estimates Using Contiguous Counties.” Review of Economics and Statistics, Vol. 92, No. 4, November, pp. 945-64.

Fairris, David, and Leon Fernandez Bujanda. 2008. "The Dissipation of Minimum Wage Gains for Workers through Labor-Labor Substitution: Evidence from the Los Angeles Living Wage Ordinance.” 
Southern Economic Journal, Vol. 75, No. 2, October, pp. 473-96.

Giuliano, Laura. "Minimum Wage Effects on Employment, Substitution, and the Teenage Labor Supply: Evidence from Personnel Data.” Forthcoming in Journal of Labor Economics.

Hirsch, Barry T., Bruce E. Kaufman, and Tetyana Zelenska. 2011. "Minimum Wage Channels of Adjustment.” Andrew Young School of Policy Studies Research Paper Series No. 11-34.

Hodrick, Robert J., and Edward C. Prescott, 1997. "Postwar U.S. Business Cycles: An Empirical Investigation.” Journal of Money, Credit and Banking, Vol. 29, No. 1, February, pp. 1-16.

Katz, Lawrence F., and Alan B. Krueger. 1992. "The Effect of the Minimum Wage on the Fast-Food Industry.” Industrial and Labor Relations Review, Vol. 46, No. 1, October, pp. 6-21.

Lang, Kevin, and Shulamit Kahn. 1998. “The Effect of Minimum-Wage Laws on the Distribution of Employment: Theory and Evidence.” Journal of Public Economics, Vol. 69, No. 1, July, pp. 67-82.

Lester, Richard A. 1960. “Employment Effects of Minimum Wages: Comment.” Industrial and Labor Relations Review, Vol. 13, No. 2, January, pp. 254-64.

Lester, Richard A. 1946. "Shortcomings of Marginal Analysis for Wage-Employment Problems." American Economic Review, Vol. 36, No. 1, March, pp. 63-82.

Machlup, Fritz. 1946. "Marginal Analysis and Empirical Research.” American Economic Review, Vol. 36, No. 4, September, pp. 519-54.

Mincer, Jacob. 1976. “Unemployment Effects of Minimum Wages.” Journal of Political Economy, Vol. 84, No. 3, Part 2, August, pp. S87-S104.

Neumark, David, Mark Schweitzer, and William Wascher. 2004. "Minimum Wage Effects Throughout the Wage Distribution.” Journal of Human Resources, Vol. 39, No. 2, Spring, pp. 425-50.

Neumark, David, and William Wascher. 2011. "Does a Higher Minimum Wage Enhance the Effectiveness of the Earned Income Tax Credit?” Industrial and Labor Relations Review, Vol. 64, No. 4, July, pp. 712-46.

Neumark, David, and William L. Wascher. 2008. Minimum Wages. Cambridge, MA: MIT Press.

Neumark, David, and William Wascher. 2004. "Minimum Wages, Labor Market Institutions, and Youth Employment: A Cross-National Analysis.” Industrial and Labor Relations Review, Vol. 57, No. 2, January, pp. 223-46.

Neumark, David, and William Wascher. 1996. "The Effects of Minimum Wages on Teenage Employment and Enrollment: Estimates from Matched CPS Data.” Research in Labor Economics, Vol. 15, pp. 25-64.

Neumark, David, and William Wascher. 1994. "Employment Effects of Minimum and Subminimum Wages: Reply to Card, Katz, and Krueger.” Industrial and Labor Relations Review, Vol. 47, No. 3, April, pp. 497-512.

Neumark, David, and William Wascher. 1992. "Employment Effects of Minimum and Subminimum Wages: Panel Data on State Minimum Wage Laws.” Industrial and Labor Relations Review, Vol. 46, No. 1, October, pp. 55-81.

Obenauer, Marie L., and Bertha von der Nienburg. 1915. "Effect of Minimum-Wage Determination in Oregon.” Bureau of Labor Statistics Bulletin No. 176. Washington, DC: United States Department of Labor.

Peterson, John M. 1960. “Employment Effects of Minimum Wages: Reply.” Industrial and Labor Relations Review, Vol. 13, No. 2, January, pp. 264-73.

Peterson, John M. 1959. "Employment Effects of State Minimum Wages for Women: Three Historical Cases Re-Examined.” Industrial and Labor Relations Review, Vol. 12, No. 3, April, pp. 406-22. 
Peterson, John M. 1957. “Employment Effects of Minimum Wages: 1938-1950.” Journal of Political Economy, Vol. 65, No. 5, October, pp. 412-30.

Ravn, Morten O., and Harald Uhlig. 2002. "On Adjusting the Hodrick-Prescott Filter for the Frequency of Observations.” The Review of Economics and Statistics, Vol. 84, No. 2, May, pp. 371-80.

Reich, Michael. 2009. "Minimum Wages in the United States: Politics, Economics, and Econometrics. In Labor in the Era of Globalization, Brown, Eichengreen, and Reich, eds. Cambridge, UK: Cambridge University Press, pp. 353-74.

Sabia, Joseph J. 2009. “The Effects of Minimum Wage Increases on Retail Employment and Hours: New Evidence from Monthly CPS Data.” Journal of Labor Research, Vol. 30, No. 1, March, pp. 75-97.

Sabia, Joseph J., Richard V. Burkhauser, and Benjamin Hansen. 2012. "Are the Effects of Minimum Wage Increases Always Small? New Evidence from a Case Study of New York State.” Industrial and Labor Relations Review, Vol. 65, No. 2, April, pp. 350-76.

Smith, Christopher L. 2010. "The Polarization of the U.S. Adult Labor Market and its Effects on the Demand for Teenage Labor.” Unpublished paper, Federal Reserve Board of Governors.

Stigler, George J. 1946. “The Economics of Minimum Wage Legislation.” American Economic Review, Vol. 42, No. 3, January, pp. 347-54.

Thompson, Jeffrey P. 2009. "Using Local Labor Market Data to Re-Examine the Employment Effects of the Minimum Wage.” Industrial and Labor Relations Review, Vol. 62, No. 3, April, pp. 343-66. 
Figure 1: Residual Plots for California

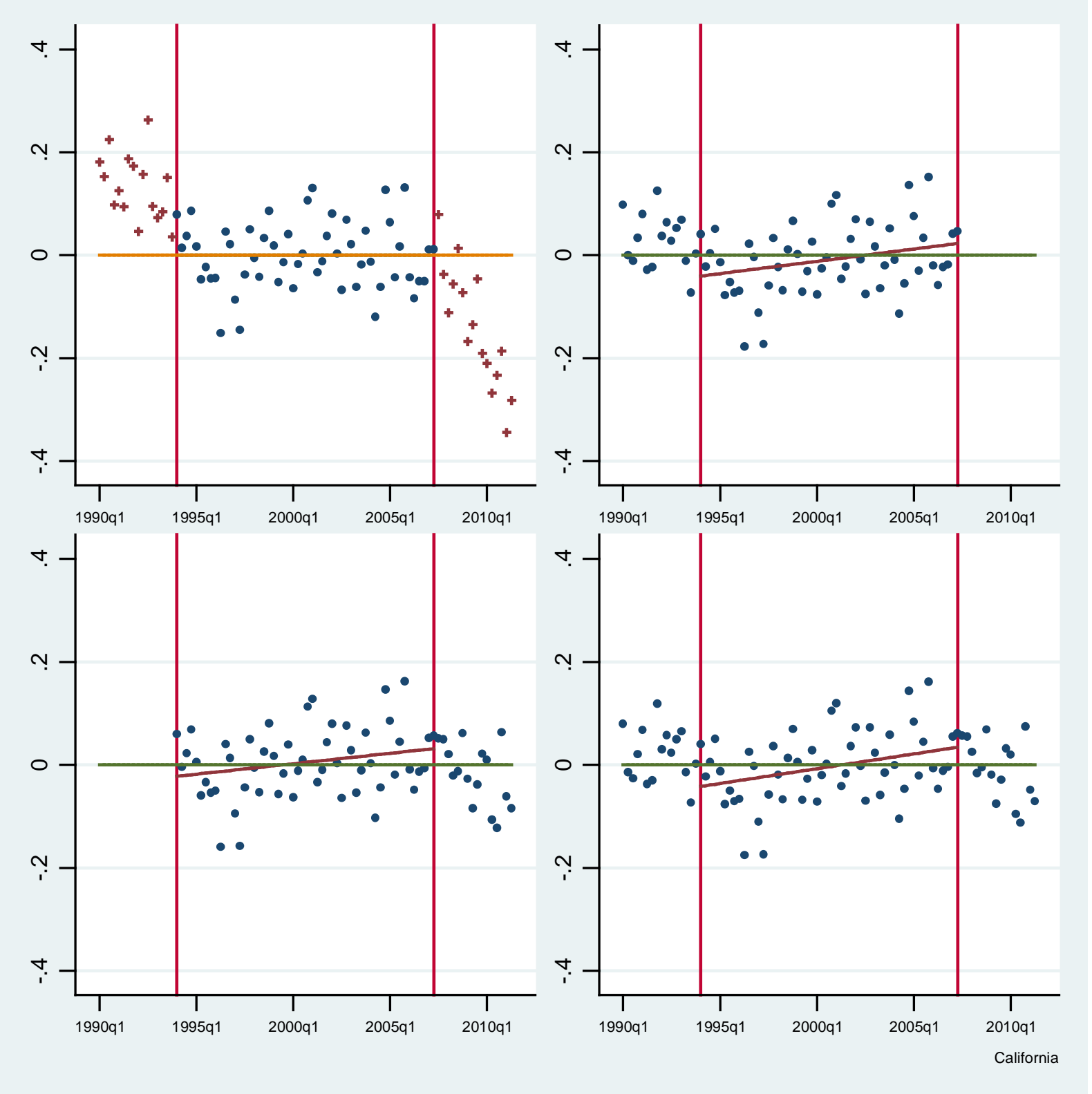

The upper-left panel shows the residuals from estimating the model with state-specific linear trends for 1994-2007:Q2; for the quarters outside this period prediction errors are shown. The lower-left, upperright, and lower-right panels, respectively, show the residuals for the following estimation periods: 1990-2007:Q2; 1994-2011:Q2; and 1990-2011:Q2. These three panels also display the fitted regression lines of the residuals on the time trend for the 1994-2007:Q2 subperiod. 
Figure 2: Between- and Within-Census Division Variation in State Minimum Wages (Difference Relative to Federal Minimum Wage, in Dollars per Hour)
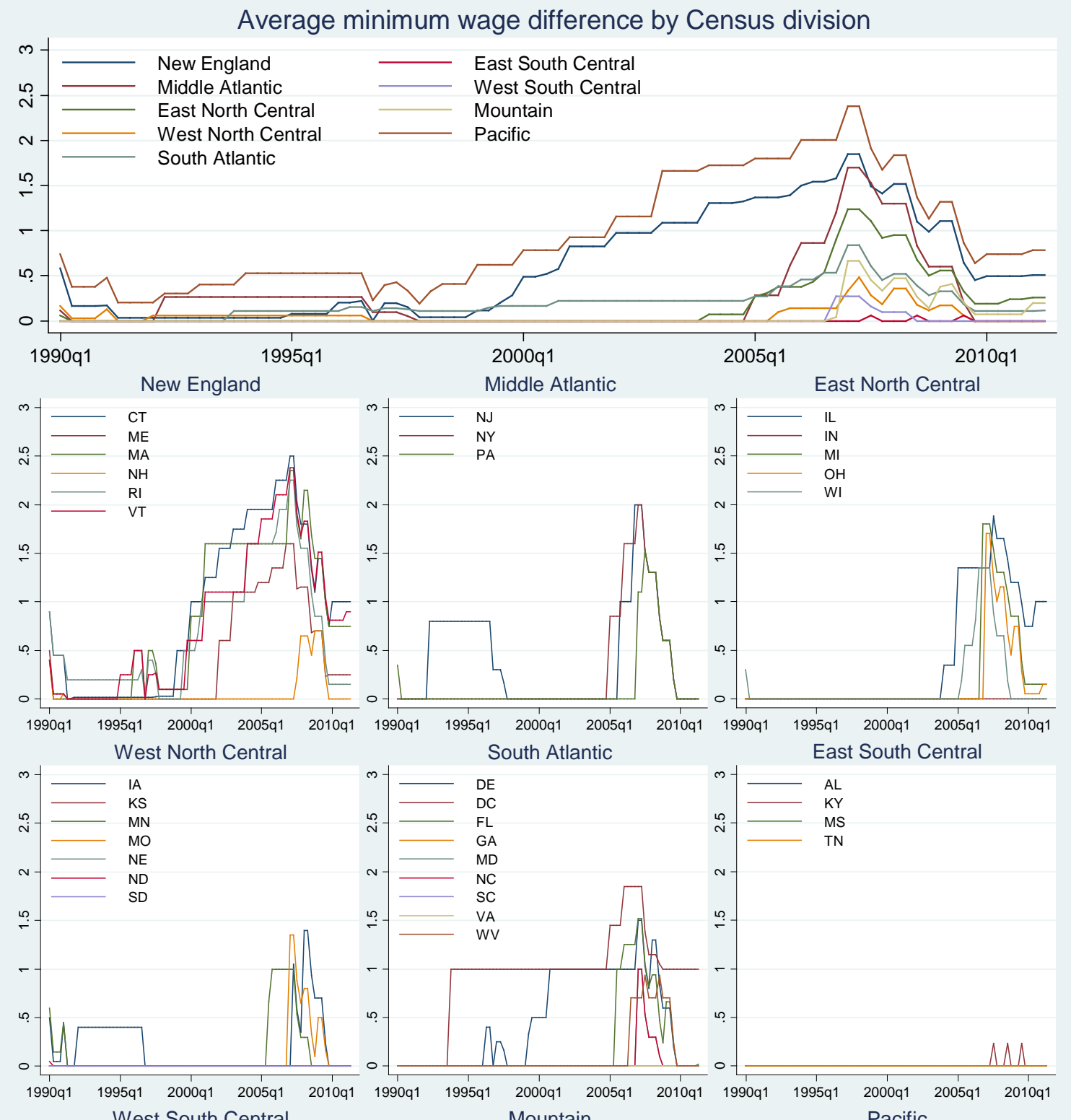

East South Central
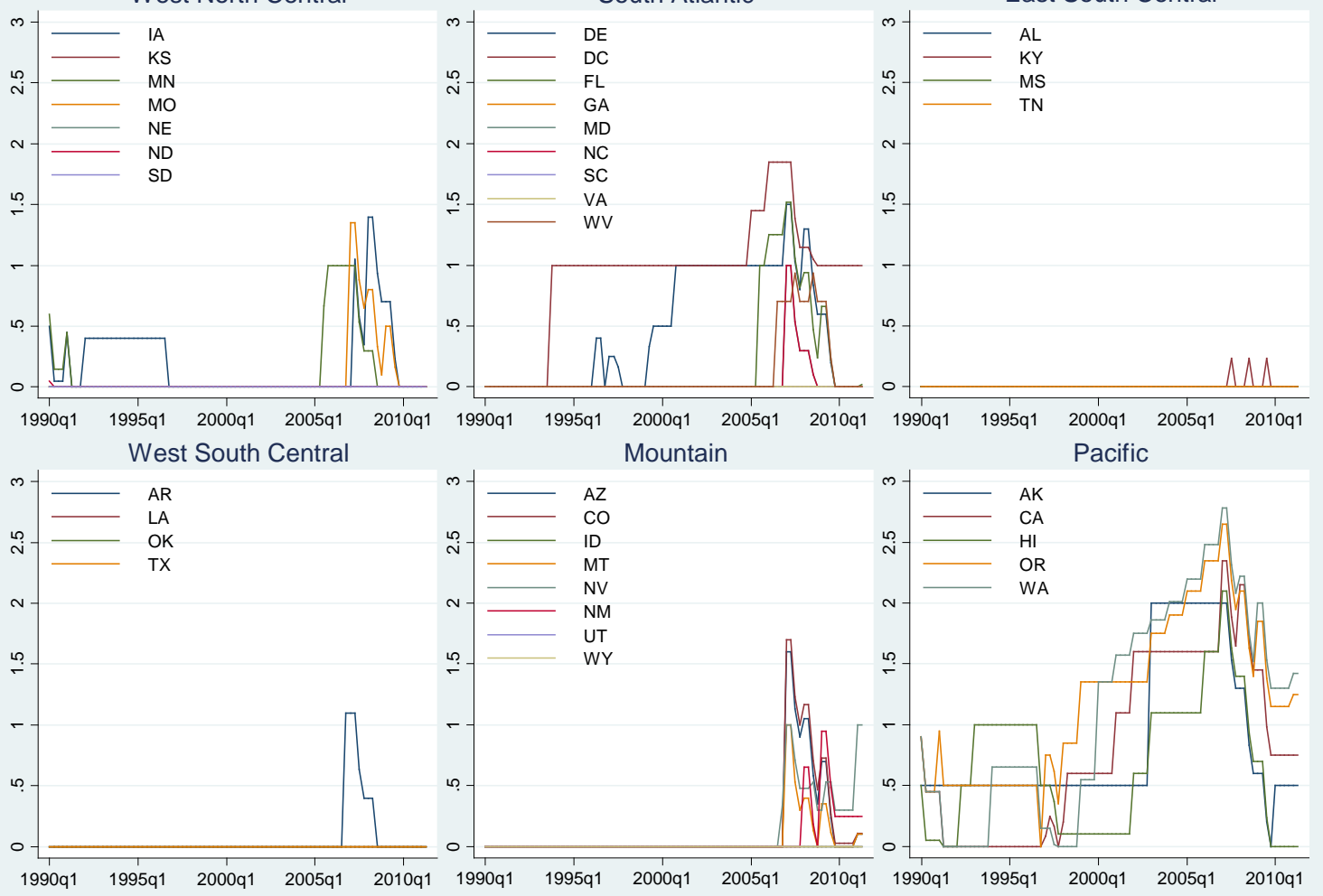
Figure 3: Example of RMSPE Calculation at State Level
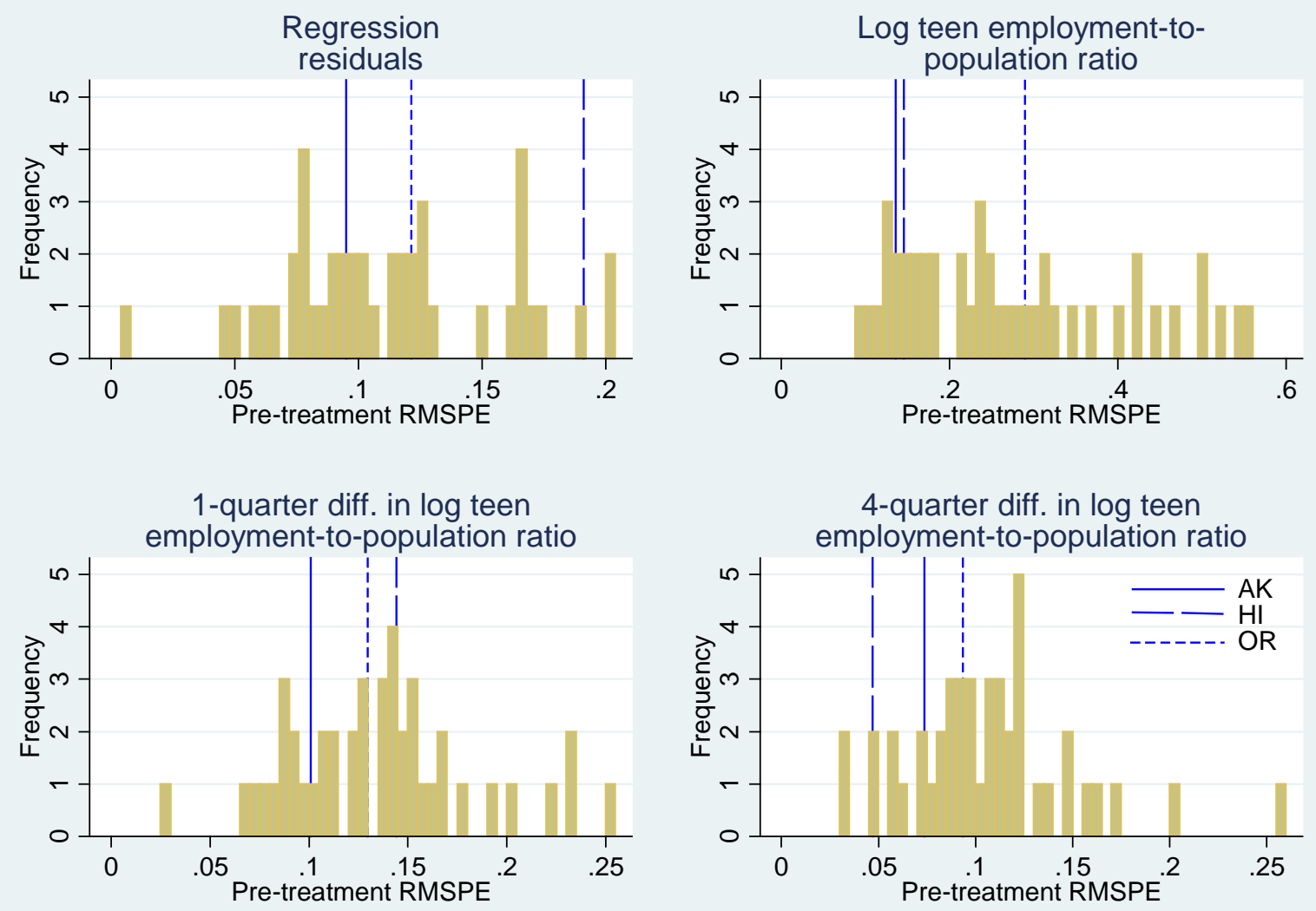

Treatment state: CA, 2001:Q1. Same-division control states are AK, HI, and OR. (WA is excluded because it had a minimum wage increase in the same quarter.) The thick bars are the histogram. The thin vertical lines extending to the top of the graph show the placement of the RMSPEs for each control state in the same division as the treatment state. 
Figure 4: Distributions of Percentiles of Same-Division States' RMSPEs

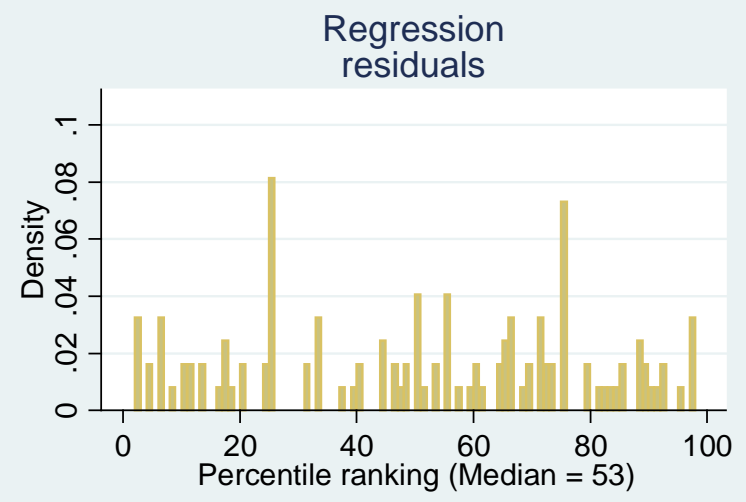

Log teen employment-topopulation ratio

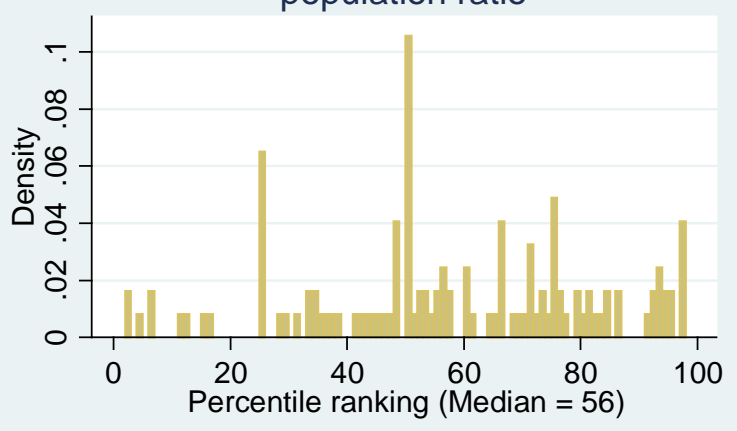

1-quarter diff. in log teen

4-quarter diff. in log teen employment-to-population ratio
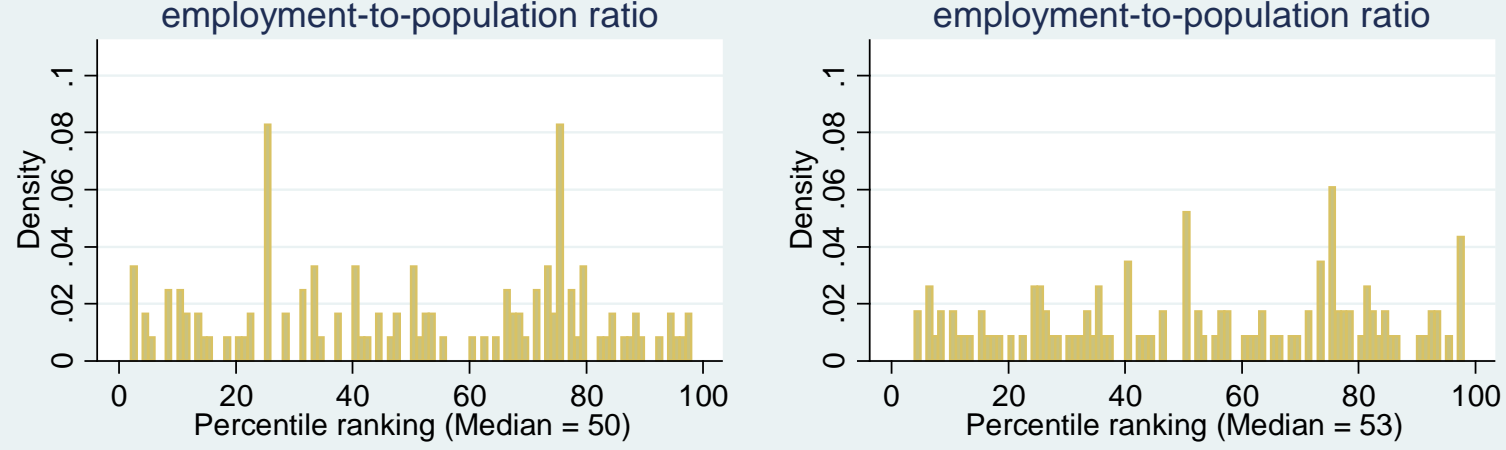

Ranks are converted to percentile rankings using the Weibull rule described in the text. 
Figure 5: Matched County Pairs Along State Borders for DLR Analysis

A. DLR's Figure 2, eyeballed

(81 state borders with MW differential over 1990:Q1-2006:Q2)

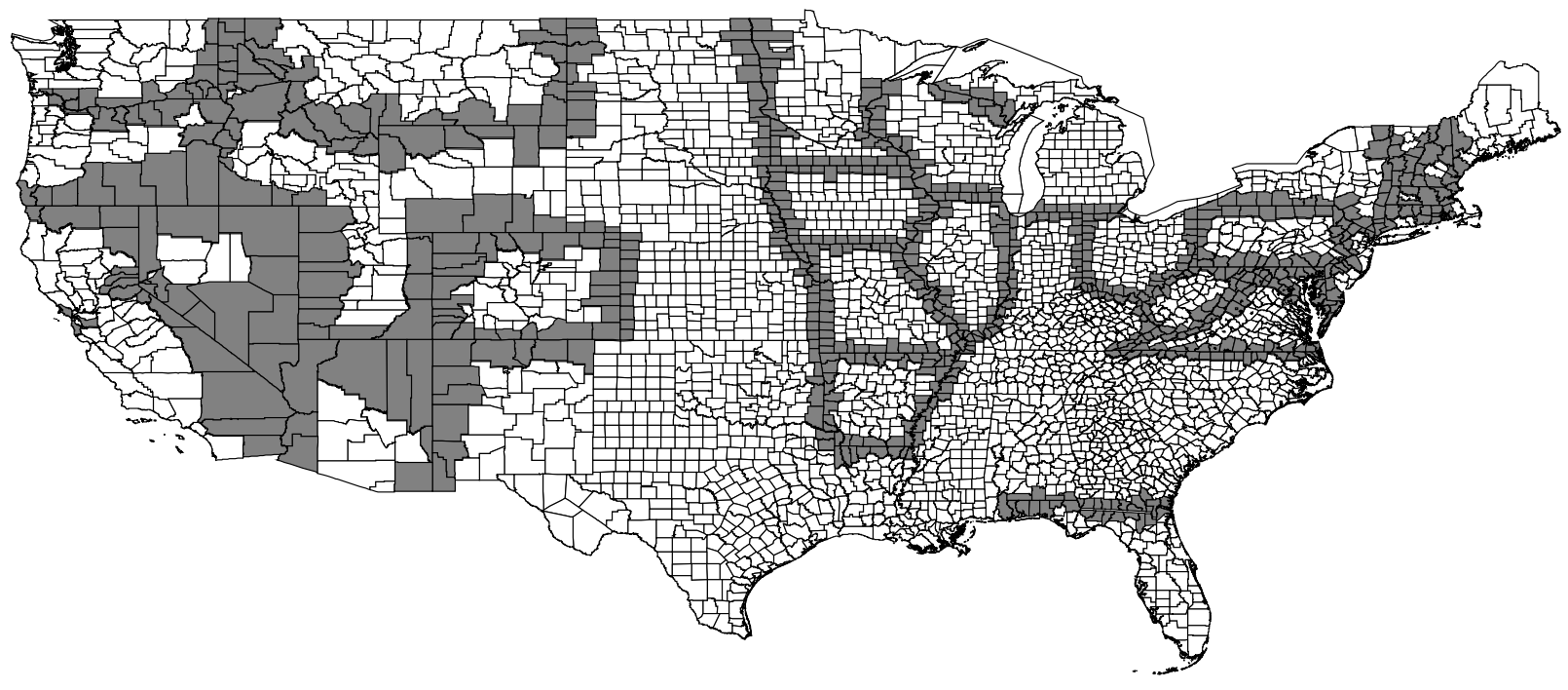

B. Corrected version of DLR's Figure 2, using their minimum wage data (48 state borders with MW differential over 1990:Q1-2006:Q2)

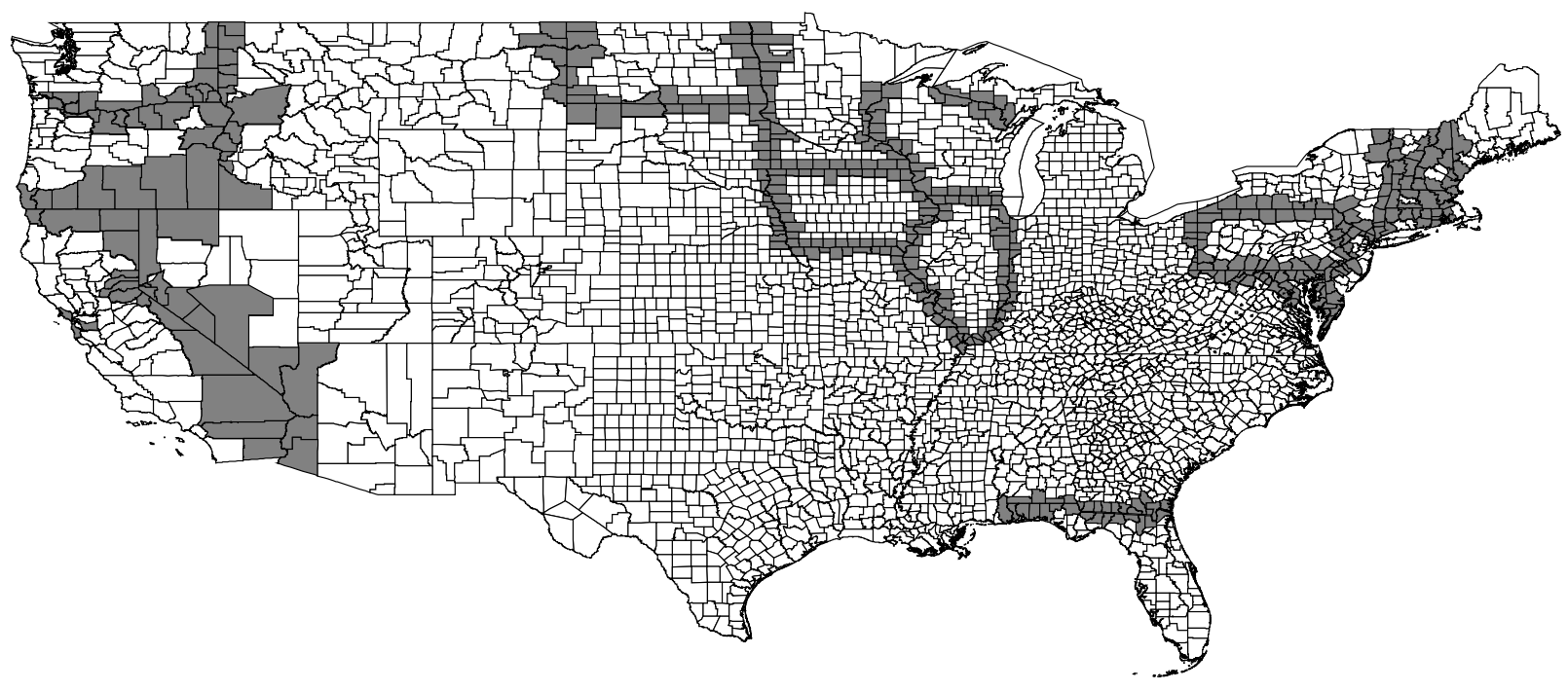


Figure 6: Distributions of Percentiles of Contiguous Cross-Border Counties' RMSPEs
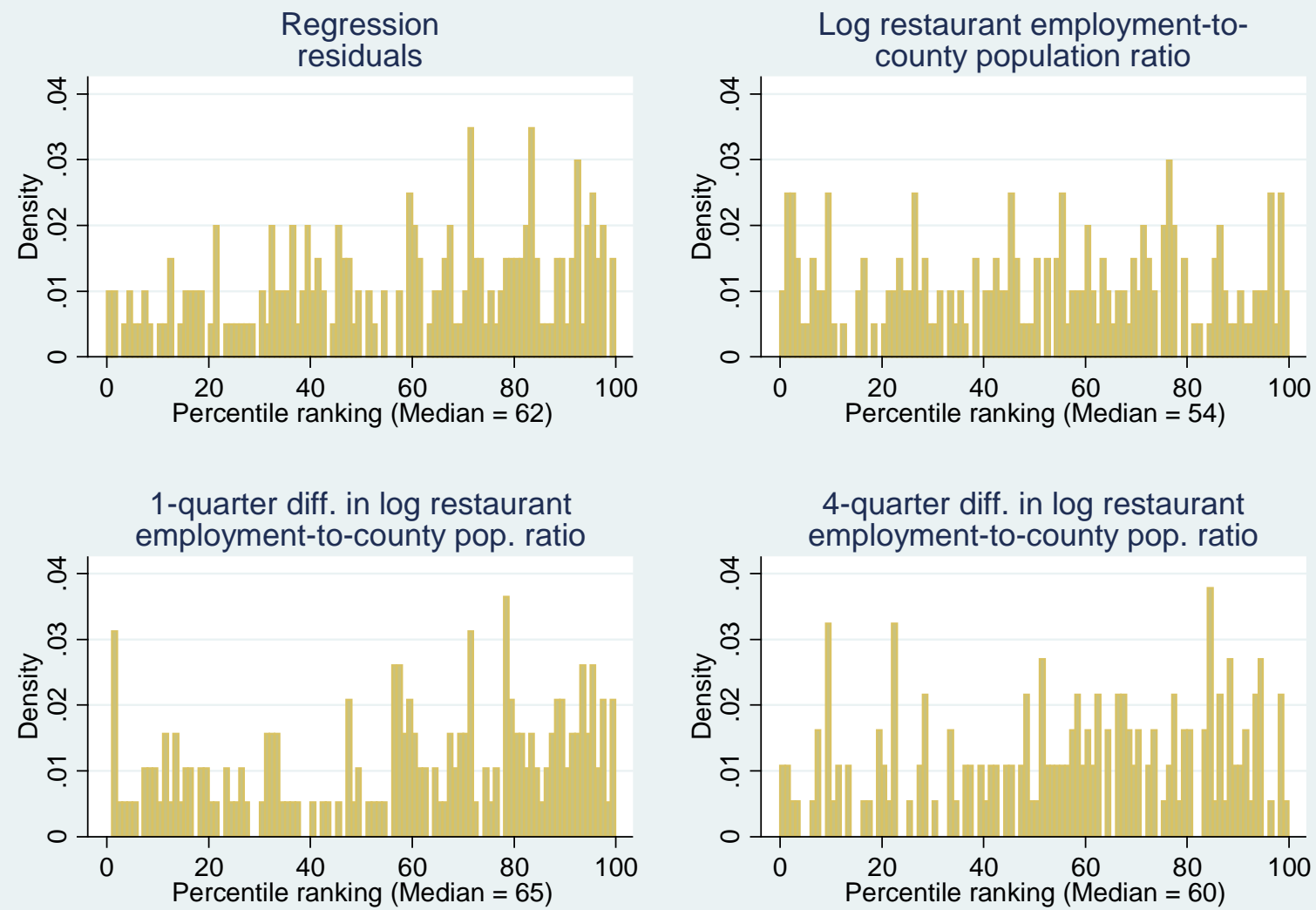

Ranks are converted to percentile rankings using the Weibull rule described in the text. 
Figure 7: Time Path of Cumulative Employment Elasticity in Response to Minimum Wage Change, ADR

\section{Specification 1}

A. Annual leads and lags (ADR Figure 2B)

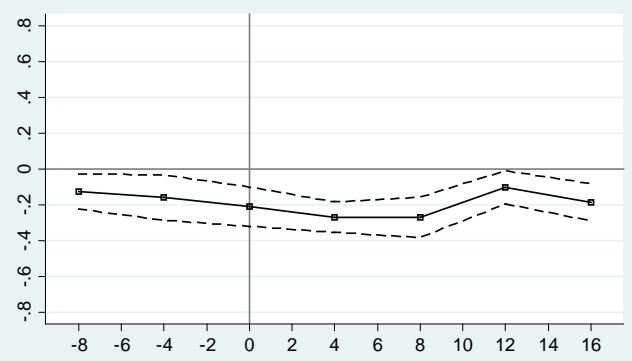

B. Quarterly leads and lags

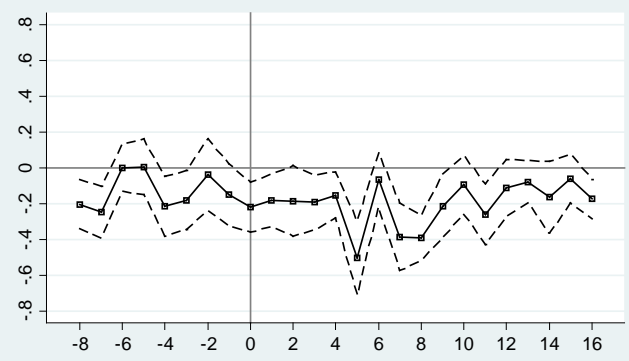

Specification 4
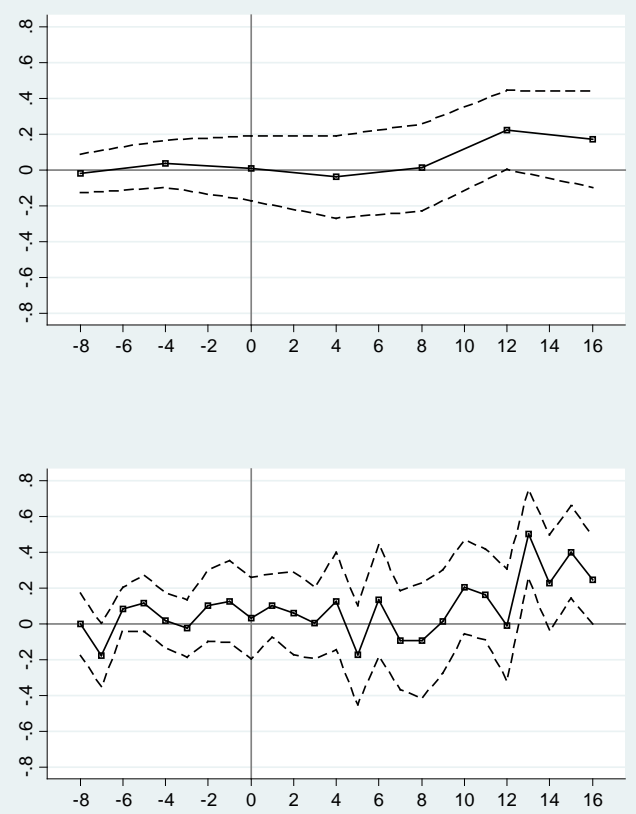

"Specification 1" is the specification with state and period fixed effects. "Specification 4" also includes the state-specific linear trends and the division $\times$ period interactions. The top graphs use the data from ADR (2011) and replicate the employment results in Figure 2 from that paper, with annual leads and lags of the minimum wage variable. The bottom graphs use the same data but include leads and lags at a quarterly frequency, which corresponds to the frequency of the minimum wage variable used in all of the regression analyses in ADR. The dashed lines show 90-percent confidence intervals. 


\section{Figure 8: Time Path of Cumulative Employment Elasticity in Response to Minimum Wage Change, DLR}

\section{Specification 1}

A. Semiannual leads and lags (DLR Figure 4)

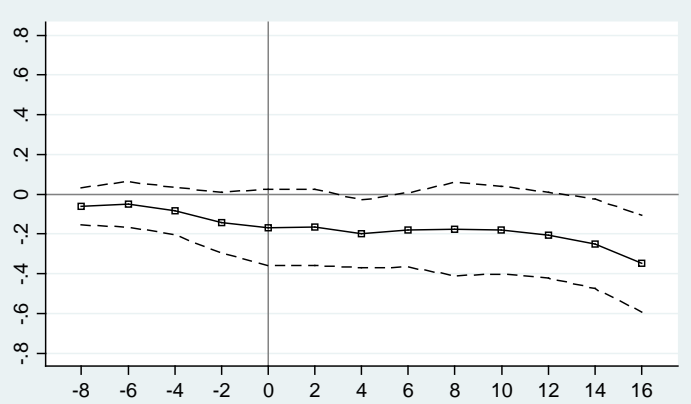

B. Quarterly leads and lags

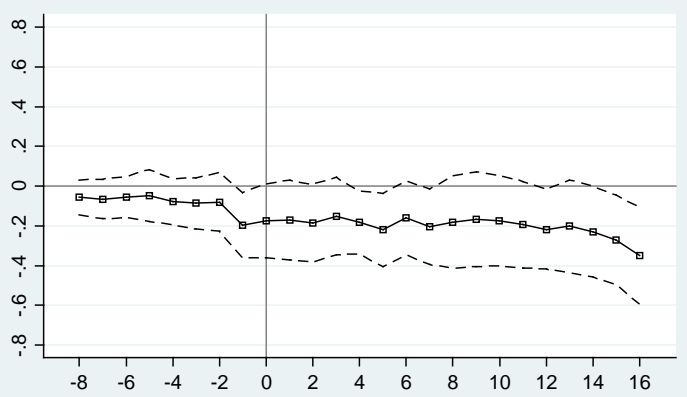

Specification 3
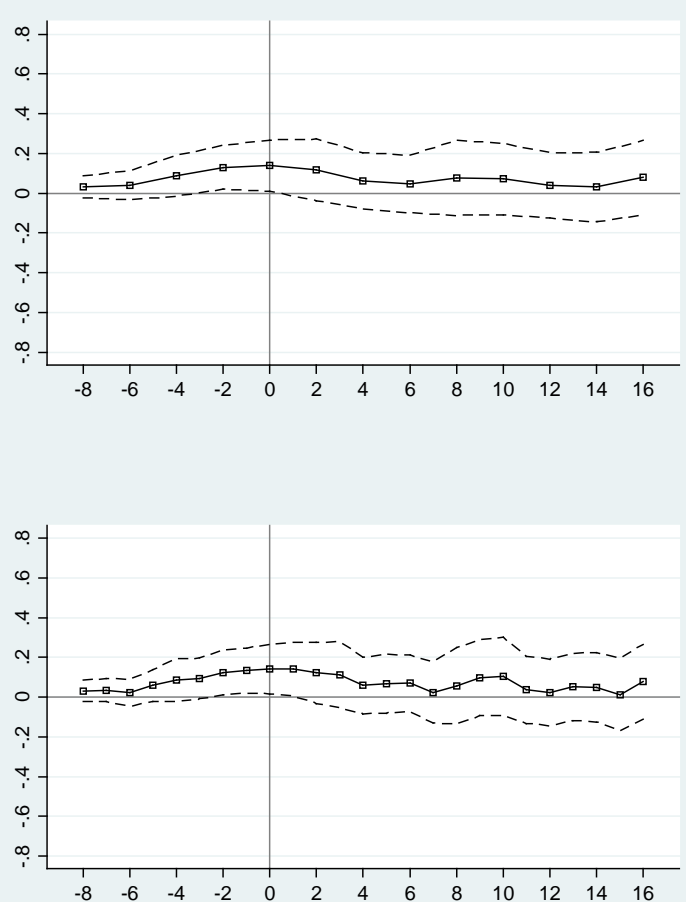

Specification 6
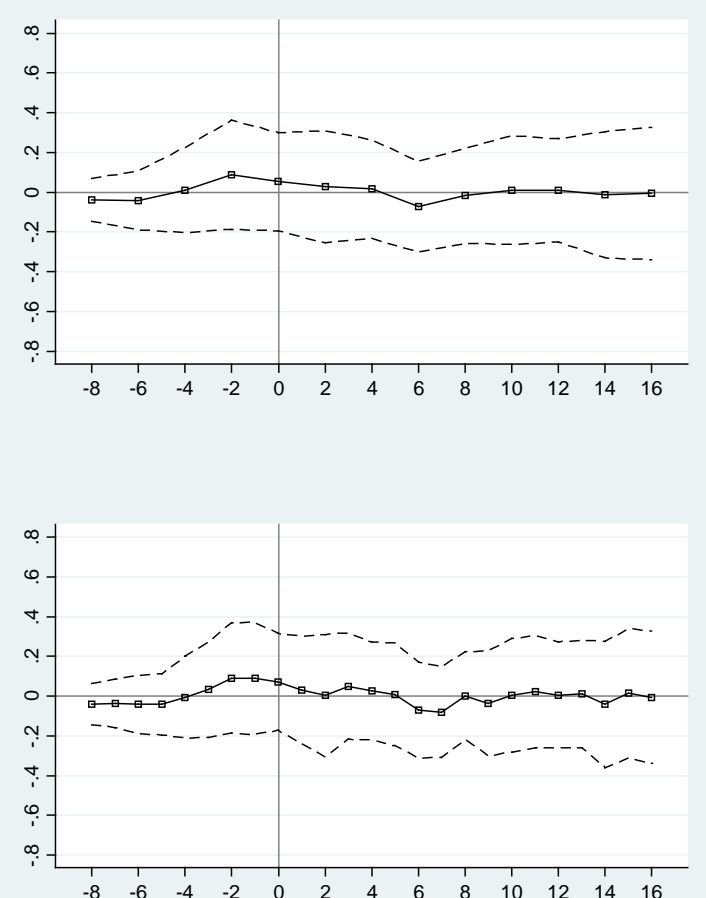

"Specification 1" is the specification with county and period fixed effects. "Specification 3" also includes the state-specific linear trends and the Census division $\times$ period interactions. "Specification 6" includes county-pair $\times$ period interactions. Specifications 1 and 3 use the allcounty sample, while Specification 6 uses the contiguous border county-pair sample. The top graphs use the data from DLR (2010) and replicate the employment results in Figure 4 from that paper, with semi-annual leads and lags of the minimum wage variable. The bottom graphs use the same data but include leads and lags at a quarterly frequency, which corresponds to the frequency of the minimum wage variable used in all of the regression analyses in DLR. The dashed lines show 90-percent confidence intervals. 
Table 1: The Effects of the Minimum Wage on Teen (16-19) Employment, 1990 - 2011:Q2

\begin{tabular}{|l|c|c|c|c|}
\hline & $(1)$ & $(2)$ & $(3)$ & $(4)$ \\
\hline & \multicolumn{4}{|c|}{ Dependent variable: Log (Employment/Population) } \\
\hline Log(MW) & $\begin{array}{c}-.165^{* * *} \\
(.041)\end{array}$ & $\begin{array}{c}-.074 \\
(.102)\end{array}$ & $\begin{array}{c}-.098 \\
(.097)\end{array}$ & $\begin{array}{c}.009 \\
(.058)\end{array}$ \\
\hline Unemployment rate & $\begin{array}{c}-4.20^{* * *} \\
(.427)\end{array}$ & $\begin{array}{c}-3.83^{* * *} \\
(.387)\end{array}$ & $\begin{array}{c}-3.86^{* * *} \\
(.403)\end{array}$ & $\begin{array}{c}-3.12^{* * *} \\
(.397)\end{array}$ \\
\hline $\begin{array}{l}\text { Relative size of youth } \\
\text { population }\end{array}$ & $\begin{array}{c}.100 \\
(.316)\end{array}$ & $\begin{array}{c}.218 \\
(.336)\end{array}$ & $\begin{array}{c}.126 \\
(.360)\end{array}$ & $\begin{array}{c}.161 \\
(.310)\end{array}$ \\
\hline State effects & Yes & Yes & Yes & Yes \\
\hline Time effects & Yes & Yes & Yes & Yes \\
\hline State trends & No & Yes & No & Yes \\
\hline $\begin{array}{l}\text { Region-specific time } \\
\text { effects }\end{array}$ & No & No & Yes & Yes \\
\hline $\mathrm{R}^{2}$ & .877 & .893 & .911 & .921 \\
\hline $\mathrm{N}$ & 4386 & 4386 & 4386 & 4386 \\
\hline
\end{tabular}

Estimates are weighted by teen population. Standard errors are clustered at the state level. $* * *, * *$, and $*$ indicate estimates that are statistically different from zero at the one-, five-, and ten-percent levels, respectively. 
Table 2: Sensitivity of Minimum Wage Effects to Polynomial Order of State-Specific “Trends,” and Estimates Using Alternative Detrending Methods, 1990 - 2011:Q2

\begin{tabular}{|c|c|c|c|c|c|c|c|c|}
\hline & (1) & $(2)$ & (3) & (4) & & (5) & $(6)$ & (7) \\
\hline & \multicolumn{8}{|c|}{ Dependent variable: $\log ($ Employment/Population) } \\
\hline $\begin{array}{l}\text { Order of polynomial } \\
\text { for state-specific } \\
\text { "trends" }\end{array}$ & $2^{\text {nd }}$ & $3^{\text {rd }}$ & $4^{\text {th }}$ & $5^{\text {th }}$ & $\begin{array}{l}\text { Detrending } \\
\text { method }\end{array}$ & $\begin{array}{l}\text { Single trends, } \\
\text { estimated from } \\
\text { subperiod } \\
\text { excluding severe } \\
\text { recessions }\end{array}$ & $\begin{array}{l}\text { Peak-to-peak } \\
\text { trends }\end{array}$ & $\begin{array}{c}\text { HP filter } \\
(\lambda=1600)\end{array}$ \\
\hline $\log (\mathrm{MW})$ & $\begin{array}{l}-0.051 \\
(0.85)\end{array}$ & $\begin{array}{c}-0.230^{* * *} \\
(0.073)\end{array}$ & $\begin{array}{l}-0.180^{* *} \\
(0.069)\end{array}$ & $\begin{array}{c}-0.185^{* *} \\
(0.073)\end{array}$ & & $\begin{array}{l}-.178^{* *} \\
(.090)\end{array}$ & $\begin{array}{l}-.319^{* *} \\
(.126)\end{array}$ & $\begin{array}{c}-.184^{* * *} \\
(.068)\end{array}$ \\
\hline Unemployment rate & $\begin{array}{c}-3.591^{* * *} \\
(0.494)\end{array}$ & $\begin{array}{c}-2.571^{* *} \\
(0.454)\end{array}$ & $\begin{array}{c}-2.376^{* *} \\
(0.461)\end{array}$ & $\begin{array}{c}-2.378^{* * *} \\
(0.492)\end{array}$ & & $\begin{array}{c}-3.06^{* * *} \\
(.307)\end{array}$ & $\begin{array}{l}-3.52^{* * *} \\
(.760)\end{array}$ & $\begin{array}{l}-2.38^{* * *} \\
(.468)\end{array}$ \\
\hline $\begin{array}{l}\text { Relative size of youth } \\
\text { population }\end{array}$ & $\begin{array}{c}0.490 \\
(0.296)\end{array}$ & $\begin{array}{c}0.402 \\
(0.280)\end{array}$ & $\begin{array}{c}0.412 \\
(0.291)\end{array}$ & $\begin{array}{c}0.354 \\
(0.308)\end{array}$ & & $\begin{array}{l}.112 \\
(.285)\end{array}$ & $\begin{array}{l}.650 \\
(.486)\end{array}$ & $\begin{array}{c}.304 \\
(.280)\end{array}$ \\
\hline $\mathrm{N}$ & 4386 & 4386 & 4386 & 4386 & & 4386 & 4386 & 4386 \\
\hline
\end{tabular}

Estimates are weighted by teen population. Standard errors are clustered at state level. In columns (1)-(4), models include state dummy variables interacted with a polynomial in time, with order of polynomial as indicated. In column (5), state-specific trends are estimated from 1994:Q1-2007:Q2 and then extrapolated to 1990:Q1-2011:Q2. (These estimates are based on equations (1) and (2) in the text.) In column (6), the peaks are based on NBER business cycle dates. In column (7), as noted in the text, $\lambda$ is the smoothing parameter for the HP filter and is set to the value commonly used for quarterly data. For columns (5)-(7), standard errors are block bootstrapped by state using 200 replications. ${ }^{* * *}, * *$, and * indicate estimated effects that are statistically different from zero at the one-, five-, and ten-percent levels, respectively (based on the normal approximation in columns (5)-(7). 
Table 3: The Effects of the Minimum Wage on Teen (16-19) Employment, By Division

\begin{tabular}{|c|c|c|}
\hline & (1) & (2) \\
\hline & \multicolumn{2}{|c|}{ Dependent variable: Log (Employment/Population) } \\
\hline & 1990:Q1-2011:Q2 & $\begin{array}{l}\text { 1990:Q1-2009:Q4 } \\
\text { (ADR sample) }\end{array}$ \\
\hline New England & $\begin{array}{c}-.390^{* * *} \\
(.052)\end{array}$ & $\begin{array}{c}-.384^{* * *} \\
(.058)\end{array}$ \\
\hline Mid-Atlantic & $\begin{array}{l}.166 \\
(.143)\end{array}$ & $\begin{array}{l}.105 \\
(.162)\end{array}$ \\
\hline East North Central & $\begin{array}{l}-.208 \\
(.284)\end{array}$ & $\begin{array}{l}-.166 \\
(.272)\end{array}$ \\
\hline West North Central & $\begin{array}{l}-.191^{* *} \\
(.082)\end{array}$ & $\begin{array}{c}-.194^{* * *} \\
(.067)\end{array}$ \\
\hline South Atlantic & $\begin{array}{l}-.150 \\
(.242)\end{array}$ & $\begin{array}{l}-.152 \\
(.281)\end{array}$ \\
\hline East South Central & $\begin{array}{l}-2.24 \\
(1.41)\end{array}$ & $\begin{array}{l}-2.02 \\
(1.51)\end{array}$ \\
\hline West South Central & $\begin{array}{c}-.217^{* * *} \\
(.062)\end{array}$ & $\begin{array}{l}-.147^{* *} \\
(.053)\end{array}$ \\
\hline Mountain & $\begin{array}{c}-.598^{* * *} \\
(.139)\end{array}$ & $\begin{array}{c}-.638^{* * *} \\
(.187)\end{array}$ \\
\hline Pacific & $\begin{array}{l}-.002 \\
(.133)\end{array}$ & $\begin{array}{l}.016 \\
(.143)\end{array}$ \\
\hline
\end{tabular}

The specification reported in each row, for a division, includes the unemployment rate, the ratio of teen population to total population, and state and time (quarter) fixed effects. Estimates are weighted by teen population. Standard errors are clustered at the state level. ***,**, and * indicate estimated effects that are statistically different from zero at the one-, five-, and ten-percent levels, respectively. 
Table 4: Weights on States in Same Census Division from Synthetic Control Estimator, State-Level CPS Data

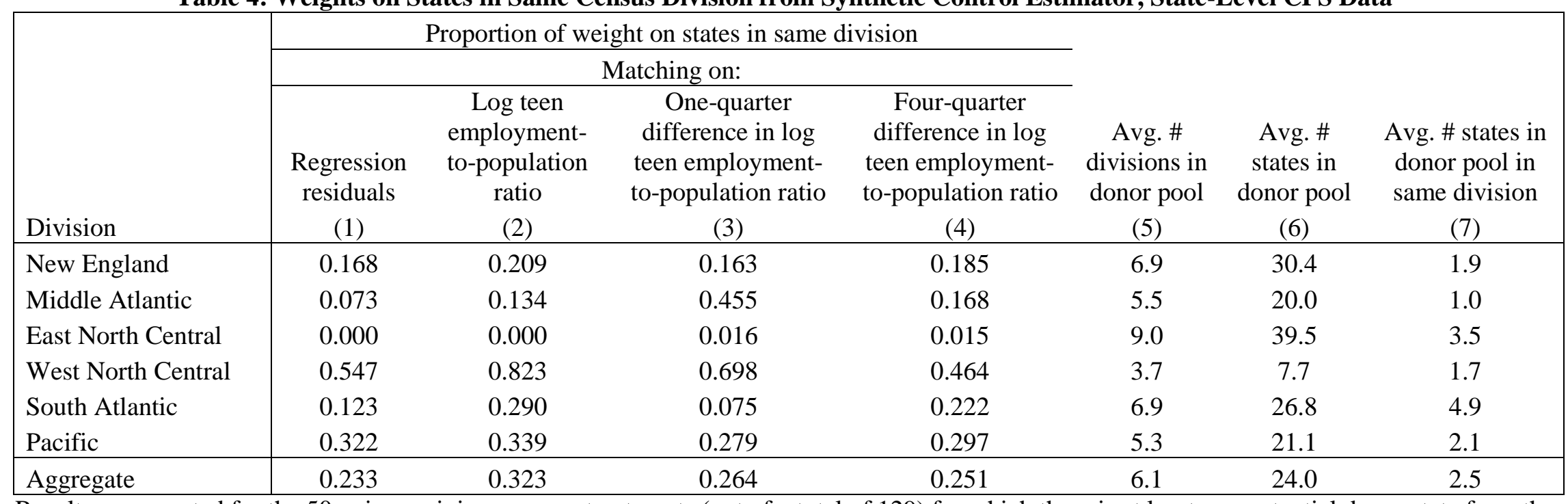

Results are reported for the 50 unique minimum wage treatments (out of a total of 129) for which there is at least one potential donor state from the same Census division. The numbers in columns (5)-(7) refer to the matching on residuals or the log teen employment-to-population ratio. There are somewhat fewer treatments and donors when matching on the one- or four-quarter differences in the employment-to-population ratio because the earliest lags are not available at the beginning of the sample period. The aggregate row reports the means across all treatment units. 
Table 5: The Effects of the Minimum Wage on Restaurant Employment, 1990-2006:Q2

\begin{tabular}{|l|c|c|c|c|}
\hline & $(1)$ & $(2)$ & $(3)$ & $(4)$ \\
\hline & \multicolumn{2}{|c|}{$\begin{array}{c}\text { Dependent variable: log (restaurant employment), } \\
\text { DLR contiguous border county-pair sample }\end{array}$} \\
\hline & \multicolumn{2}{|c|}{$\begin{array}{c}\text { Without county-pair } \times \\
\text { period interactions } \\
\text { (DLR, Table 2, } \\
\text { specification 5) }\end{array}$} & \multicolumn{2}{|c|}{$\begin{array}{c}\text { With county-pair } \times \\
\text { period interactions } \\
\text { (DLR, Table 2, } \\
\text { specification 6) }\end{array}$} \\
\hline Log(MW) & $\begin{array}{l}-.137^{*} \\
(.072)\end{array}$ & $\begin{array}{c}-.112 \\
(.079)\end{array}$ & $\begin{array}{c}.057 \\
(.115)\end{array}$ & $\begin{array}{c}.016 \\
(.099)\end{array}$ \\
\hline Log(population) & $\begin{array}{c}.952^{* * *} \\
(.073)\end{array}$ & $\begin{array}{c}.567^{* * *} \\
(.103)\end{array}$ & $\begin{array}{c}1.116^{* * *} \\
(.190)\end{array}$ & $\begin{array}{c}.714^{* * *} \\
(.246)\end{array}$ \\
\hline $\begin{array}{l}\text { Log(private-sector } \\
\text { employment) }\end{array}$ & $\ldots$ & $\begin{array}{c}.405^{* * *} \\
(.067)\end{array}$ & $\ldots$ & $\begin{array}{c}.393^{* * *} \\
(.117)\end{array}$ \\
\hline County effects & Yes & Yes & Yes & Yes \\
\hline Period effects & Yes & Yes & No & No \\
\hline $\begin{array}{l}\text { County-pair } \times \text { period } \\
\text { interactions }\end{array}$ & No & No & Yes & Yes \\
\hline N & 70,620 & 70,582 & 70,620 & 70,582 \\
\hline
\end{tabular}

Standard errors are two-way clustered at the (non-nested) state and border segment levels; the border segment is the set of all counties on both sides of a border between two states. ***,**, and * indicate estimates that are statistically different from zero at the one-, five-, and ten-percent levels, respectively. 
Table 6: Weights on Contiguous Cross-Border Counties from Synthetic Control Estimator, County-Level QCEW Data

\begin{tabular}{|c|c|c|c|c|}
\hline \multirow[b]{4}{*}{ Distribution } & \multicolumn{4}{|c|}{ Proportion of weight on contiguous cross-border counties } \\
\hline & \multicolumn{4}{|c|}{ Matching on: } \\
\hline & $\begin{array}{l}\text { Regression } \\
\text { residuals }\end{array}$ & $\begin{array}{l}\text { Log restaurant } \\
\text { employment- } \\
\text { to-county } \\
\text { population } \\
\text { ratio }\end{array}$ & $\begin{array}{l}\text { One-quarter } \\
\text { difference in log } \\
\text { restaurant } \\
\text { employment-to- } \\
\text { county population } \\
\text { ratio }\end{array}$ & $\begin{array}{c}\text { Four-quarter } \\
\text { difference in log } \\
\text { restaurant } \\
\text { employment-to- } \\
\text { county population } \\
\text { ratio }\end{array}$ \\
\hline & $(1)$ & $(2)$ & $(3)$ & $(4)$ \\
\hline \multicolumn{5}{|c|}{$\begin{array}{l}\text { A. Donor pools restricted to } 50 \text { counties with lowest RMSPE for four quarters prior to minimum } \\
\text { wage increase }\end{array}$} \\
\hline Minimum & 0.000 & 0.000 & 0.000 & 0.000 \\
\hline $10^{\text {th }}$ percentile & 0.000 & 0.000 & 0.000 & 0.001 \\
\hline $25^{\text {th }}$ percentile & 0.002 & 0.002 & 0.002 & 0.004 \\
\hline Median & 0.008 & 0.010 & 0.009 & 0.010 \\
\hline $75^{\text {th }}$ percentile & 0.029 & 0.027 & 0.027 & 0.019 \\
\hline $90^{\text {th }}$ percentile & 0.075 & 0.101 & 0.065 & 0.035 \\
\hline Maximum & 0.723 & 0.659 & 0.496 & 0.336 \\
\hline Mean & 0.033 & 0.038 & 0.035 & 0.017 \\
\hline \multicolumn{5}{|c|}{ B. Full donor pools } \\
\hline Minimum & 0.000 & 0.000 & 0.000 & 0.000 \\
\hline $10^{\text {th }}$ percentile & 0.000 & 0.000 & 0.000 & 0.000 \\
\hline $25^{\text {th }}$ percentile & 0.001 & 0.000 & 0.001 & 0.001 \\
\hline Median & 0.001 & 0.001 & 0.001 & 0.001 \\
\hline $75^{\text {th }}$ percentile & 0.002 & 0.002 & 0.002 & 0.002 \\
\hline $90^{\text {th }}$ percentile & 0.006 & 0.007 & 0.012 & 0.006 \\
\hline Maximum & 0.228 & 0.308 & 0.474 & 0.393 \\
\hline Mean & 0.006 & 0.007 & 0.015 & 0.007 \\
\hline
\end{tabular}

County results are reported for the 121 unique minimum wage treatments at the state-by-quarter level for which there is at least one potential contiguous cross-border donor county. In Panel A, for each treatment the donor pool consists of the 50 counties with the lowest RMSPE for the four quarters following the minimum wage increase. If the contiguous cross-border counties that DLR use as controls are not in this top 50, they are added to the donor pool. Panel B does not impose this restriction. In both panels, the average number of contiguous cross-border counties in the donor pool is 1.7, while the average number of counties in the donor pool is 51.3 in Panel A and 959.6 in Panel B. There are somewhat fewer treatments and donors when matching on the one- or four-quarter differences in the employment-to-population ratio because the earliest lags are not available at the beginning of the sample period. 
Table 7: The Effects of the Minimum Wage on Restaurant Employment, with Leading Effects, 1990-2006:Q2

\begin{tabular}{|c|c|c|}
\hline & (1) & (2) \\
\hline & \multicolumn{2}{|c|}{ Dependent variable: Log(restaurant employment) } \\
\hline & $\begin{array}{l}\text { All counties (DLR, Table } \\
\text { 3, specification 1) }\end{array}$ & $\begin{array}{l}\text { All counties, with state- } \\
\text { specific linear trends and } \\
\text { Census division } \times \text { period } \\
\text { interactions (DLR } \\
\text { specification } 3 \text { ) }\end{array}$ \\
\hline \multicolumn{3}{|l|}{$\begin{array}{l}\text { Cumulative effect of } \\
\log (\mathrm{MW})\end{array}$} \\
\hline 12-quarter lead & $\begin{array}{l}-.069 \\
(.058)\end{array}$ & $\begin{array}{l}.070 \\
(.047)\end{array}$ \\
\hline 4-quarter lead & $\begin{array}{l}-.192^{*} \\
(.113)\end{array}$ & $\begin{array}{l}.188^{*} \\
(.094)\end{array}$ \\
\hline $\begin{array}{l}\text { Pre-trend: 4-quarter } \\
\text { lead - 12-quarter lead }\end{array}$ & $\begin{array}{l}-.122^{*} \\
(.070)\end{array}$ & $\begin{array}{l}.117^{* *} \\
(.054)\end{array}$ \\
\hline County effects & Yes & Yes \\
\hline Period effects & Yes & No \\
\hline $\mathrm{N}$ & 82,800 & 82,800 \\
\hline
\end{tabular}

Estimates correspond to Table 3 of DLR. Standard errors are clustered at the state level. $* * *, * *$, and $*$ indicate estimates that are statistically different from zero at the one-, five-, and ten-percent levels, respectively. 
Table 8: The Effects of the Minimum Wage on Restaurant Employment, with Leading Effects, 1990-2006:Q2

\begin{tabular}{|c|c|c|c|}
\hline & (1) & $(2)$ & (3) \\
\hline & \multicolumn{3}{|c|}{ Dependent variable: Log(restaurant employment) } \\
\hline & $\begin{array}{l}\text { All counties (DLR, Table } \\
\text { 3, specification 1) }\end{array}$ & $\begin{array}{l}\text { All counties, with } \\
\text { state-specific linear } \\
\text { trends, and Census } \\
\text { division } \times \text { period } \\
\text { interactions (DLR } \\
\text { specification 3) }\end{array}$ & $\begin{array}{l}\text { DLR contiguous border } \\
\text { county-pair sample, } \\
\text { with county-pair } \times \\
\text { period interactions } \\
\text { (DLR specification 6) }\end{array}$ \\
\hline \multicolumn{4}{|c|}{ A. 12-quarter leads } \\
\hline \multicolumn{4}{|l|}{ Pre-trend: } \\
\hline $\begin{array}{l}\text { 10-quarter lead - 12- } \\
\text { quarter lead }\end{array}$ & $\begin{array}{l}-.004 \\
(.042)\end{array}$ & $\begin{array}{l}.083^{* * *} \\
(.031)\end{array}$ & $\begin{array}{l}.049 \\
(.072)\end{array}$ \\
\hline $\begin{array}{l}\text { 8-quarter lead - 12- } \\
\text { quarter lead }\end{array}$ & $\begin{array}{l}-.047 \\
(.064)\end{array}$ & $\begin{array}{l}.127^{* *} \\
(.051)\end{array}$ & $\begin{array}{c}.057 \\
(.095)\end{array}$ \\
\hline $\begin{array}{l}\text { 6-quarter lead - 12- } \\
\text { quarter lead }\end{array}$ & $\begin{array}{l}-.067 \\
(.060)\end{array}$ & $\begin{array}{l}.124^{* *} \\
(.049)\end{array}$ & $\begin{array}{l}.056 \\
(.121)\end{array}$ \\
\hline $\begin{array}{l}\text { 4-quarter lead - 12- } \\
\text { quarter lead }\end{array}$ & $\begin{array}{l}-.122^{*} \\
(.070)\end{array}$ & $\begin{array}{l}.117^{* *} \\
(.054)\end{array}$ & $\begin{array}{l}.040 \\
(.134)\end{array}$ \\
\hline $\begin{array}{l}\text { 2-quarter lead - 12- } \\
\text { quarter lead }\end{array}$ & $\begin{array}{l}-.105 \\
(.071)\end{array}$ & $\begin{array}{l}.088^{*} \\
(.052)\end{array}$ & $\begin{array}{l}.058 \\
(.143)\end{array}$ \\
\hline \multicolumn{4}{|c|}{ B. 8-quarter leads } \\
\hline $\begin{array}{l}\text { 6-quarter lead - 8- } \\
\text { quarter lead }\end{array}$ & $\begin{array}{l}-.015 \\
(.038)\end{array}$ & $\begin{array}{l}.058^{* *} \\
(.022)\end{array}$ & $\begin{array}{l}.062 \\
(.092)\end{array}$ \\
\hline $\begin{array}{l}\text { 4-quarter lead - 8- } \\
\text { quarter lead }\end{array}$ & $\begin{array}{l}-.055 \\
(.065)\end{array}$ & $\begin{array}{l}.098^{* *} \\
(.039)\end{array}$ & $\begin{array}{l}.119 \\
(.125)\end{array}$ \\
\hline $\begin{array}{l}\text { 2-quarter lead - 8- } \\
\text { quarter lead }\end{array}$ & $\begin{array}{l}-.040 \\
(.066)\end{array}$ & $\begin{array}{l}.106^{* * *} \\
(.036)\end{array}$ & $\begin{array}{l}.137 \\
(.125)\end{array}$ \\
\hline
\end{tabular}

Specifications in Panel A, columns (1) and (2) correspond to Table 9, but with the pre-trend estimated over different periods. Specifications in column (3) do the same for DLR's specification 6. Specifications in Panel B are the same, but only include leads up to 8 quarters. The two highlighted estimates are the ones reported in DLR's Table 3 for restaurant employment. These specifications exclude the private-sector employment control, although DLR include this control in the specifications on which their Figure 4 is based. Standard errors are clustered at the state level. ${ }^{* * *}$, ${ }^{* *}$, and * indicate estimates that are statistically different from zero at the one-, five-, and ten-percent levels, respectively. 
Table 9: The Effects of the Minimum Wage on Restaurant Employment, "Falsification Tests"

\begin{tabular}{|c|c|c|c|}
\hline & (1) & $(2)$ & (3) \\
\hline & \multicolumn{3}{|c|}{ Dependent variable: Log (restaurant employment) } \\
\hline & $\begin{array}{l}\text { DLR sample: 1990:Q1- } \\
\text { 2006:Q2 (Table B1, } \\
\text { specification 2) }\end{array}$ & $\begin{array}{c}\text { Sample restricted to } \\
\text { 1998:Q3-2006:Q2 } \\
\text { (period with no federal } \\
\text { MW changes) }\end{array}$ & $\begin{array}{l}\text { Sample restricted to } \\
\text { 1998:Q3-2006:Q2, county } \\
\text { pairs with minimum wage } \\
\text { difference for at least one } \\
\text { quarter }\end{array}$ \\
\hline \multicolumn{4}{|l|}{ Actual MW sample: } \\
\hline $\log (\mathrm{MW})$ & $\begin{array}{c}-0.208 \\
(0.150)\end{array}$ & $\begin{array}{c}-0.247^{* * *} \\
(0.042)\end{array}$ & $\begin{array}{c}-0.260^{* *} \\
(0.097)\end{array}$ \\
\hline $\mathrm{N}$ & 34,514 & 21,308 & 5,180 \\
\hline \multicolumn{4}{|l|}{ Placebo MW sample: } \\
\hline $\log (\mathrm{MW})$ & $\begin{array}{c}-0.123 \\
(0.158)\end{array}$ & $\begin{array}{l}-0.107 \\
(0.068)\end{array}$ & $\begin{array}{c}0.005 \\
(0.082)\end{array}$ \\
\hline $\mathrm{N}$ & 33,726 & 20,768 & 4,640 \\
\hline $\begin{array}{l}\% \text { of county pair-quarter } \\
\text { observations with } \\
\text { minimum wage } \\
\text { difference between } \\
\text { counties }\end{array}$ & 4.0 & 7.0 & 31.2 \\
\hline $\begin{array}{l}\% \text { of county pairs with } \\
\text { minimum wage } \\
\text { difference between } \\
\text { counties in sample } \\
\text { period }\end{array}$ & 17.8 & 22.3 & 100.0 \\
\hline County effects & Yes & Yes & Yes \\
\hline Period effects & Yes & Yes & Yes \\
\hline
\end{tabular}

These specifications include controls for population and private-sector employment. Following DLR's code, the sample is restricted to counties that have an area less than 2,000 square miles. In columns (2) and (3), a balanced panel of counties is used, as in DLR's other analyses; some counties that are not included in column (1) can be included in the samples in these columns. In column (3), the subset of county pairs in column (2) that had one or more minimum wage differences in the period always had at least two quarters of minimum wage differences. Standard errors are clustered at the state level. ***, **, and * indicate estimates that are statistically different from zero at the one-, five-, and ten-percent levels, respectively. 